\title{
Probing geomagnetic storm-driven magnetosphere-ionosphere dynamics in D-region via propagation characteristics of very low frequency radio signals
}

\author{
Victor U. J. Nwankwo ${ }^{\mathrm{a}}$, Sandip K. Chakrabarti ${ }^{\mathrm{a}, \mathrm{b}}$, Olugbenga \\ Ogunmodimu ${ }^{\mathrm{c}}$ \\ ${ }^{a}$ S. N. Bose National Centre for Basic Sciences, Kolkata 700098, India \\ ${ }^{b}$ Indian Centre for Space Physics, Kolkata 700084, India \\ ${ }^{c}$ Department of Physics, Lancaster University, LA1 4YW, UK
}

\begin{abstract}
The amplitude and phase of VLF/LF radio signals are sensitive to changes in electrical conductivity of the lower ionosphere which imprints its signature on the Earth-ionosphere waveguide. This characteristics makes it useful in studying sudden ionospheric disturbances, especially those related to prompt $\mathrm{X}$-ray flux output from solar flares and gamma ray bursts (GRBs). However, strong geomagnetic disturbance and storm conditions are known to produce large and global ionospheric disturbances, which can significantly affect VLF radio propagation in the $\mathrm{D}$ region of the ionosphere. In this paper, using the data of three propagation paths at mid-latitudes $\left(40^{\circ}-54^{\circ}\right)$, we analyze the trend of aspects of VLF diurnal signal under varying solar and geomagnetic space environmental conditions in order to identify possible geomagnetic footprints on the D region characteristics. We found that the trend of variations generally reflect the prevailing space weather conditions in various time scales. In particular, the 'dipping' of mid-day signal amplitude (MDP) of VLF always occurs after geomagnetic perturbed or storm conditions in the time scale of 1-2 days. The mean signal before sunrise (MBSR) and mean signal after sunset (MASS) also exhibit storm-induced dipping, but they appear to be influenced by event's exact occurrence time and highly variable conditions of dusk-to-dawn ionosphere. We observed fewer cases of the signals rise (e.g., MDP, MBSR or MASS) following a significant geomagnetic event, though this effect may be related to storms associated phenomena or
\end{abstract}


effects arising from sources other than solar origin. The magnitude of induced dipping (or rise) significantly depends on the intensity and duration of event(s), as well as the propagation path of the signal. The post-storm day signal (following a main event, with lesser or significantly reduced geomagnetic activity), exhibited a tendency of recovery to pre-storm day level. In the present analysis, We do not see a well defined trend of the variations of the post-storm sunrise terminator (SRT) and sunset terminator (SST). The SRT and SST signals show more post-storm dipping in GQD-A118 propagation path but generally an increase along DHO-A118 propagation path. Thus the result could be propagation path dependent and detailed modeling is required to understand these phenomena.

Keywords: D-region ionosphere, Geomagnetic storm, Ionospheric response, magnetosphere-ionosphere dynamics, VLF radio signals

\section{Introduction}

Although separated by thousands of kilometers, the magnetosphere and ionosphere are known to be physically connected through the Earth's magnetic field into one global system. The ionosphere responds to (a) prompt changes in solar energetic events, mainly the solar flare associated bursts in EUV, X-ray and relativistic particles (Mitra, 1974; Bounsanto, 1999; Alfonsi et al., 2008), (b) delayed changes mainly due to geomagnetic storm conditions with time scale from several hours to 1-3 days (Lastovika, 1996; Bounsanto, 1999; Kutiev, 2013), and (c) periodic changes with time scales of several days to months, and those of several solar cycles (Alfonsi, 2008; Kutiev, 2013). The ionosphere also exhibits diurnal (day/night) and seasonal (summer/winter) variations (Miller and Brace, 1969; Zhang et al., 1999). Solar and geomagnetic induced phenomena drive changes in magnetosphere conditions, whose coupling effects modify ionospheric signatures including atmospheric density distribution, total electron content (TEC), ionospheric current system, ionisation rates, and crucial D-region parameters such as conductivity gradient and reference height (Wait, 1959; Wait and Spies, 1964; Mitra, 1974; Buonsanto, 1999; Burke, 2000; Simoes et al., 2012; Nwankwo and Chakrabarti, 2014b). The dynamics of ionospheric response to changes in solar and geomagnetic conditions, involve the exchange of particles and electromagnetic energy (absorbed, reprocessed and deposited in the ionosphere by the magnetosphere) between magnetically connected regions (Burke, 2000; 
Streltsov and Lotko, 2004; Goldstein et al., 2006; Russell et al., 2010; Russell and Wright, 2012 Leonard et al., 2012; Kutiev et al., 2013).

\subsection{The ionosphere at a glance}

The ionosphere is composed of three distinct space regions [D $(50 \mathrm{~km}$ to $90 \mathrm{~km}$ ), E (90 km to $120 \mathrm{~km}$ ), and the F (from $120 \mathrm{~km}$ up to $500 \mathrm{~km}$ ), which often split into two layers, namely, F1 and F2]. Its existence is primarily due to ionisation by solar ultraviolet (UV) radiation and X-ray wavelength (Kelley, 1989; Prolss, 2004; McRae and Thomson, 2004; Raulin et al., 2006; Heikkila, 2011) and isotropic cosmic rays. Recombination also occurs when free electrons are captured by positive ions. Ionisation and recombination efficiency controls the overall electron density at every instant of time. The D region ionosphere highly active during the day (roughly between the local sunrise and sunset) due to high rate of ionisation, but its density fall significantly at night largely due to rapid recombination at the altitude. The $\mathrm{E}$ region also maintains the same dynamics (night/day fluctuations) as the $\mathrm{D}$ region but ionisation state persists longer due to slower rate of recombination at lower density. Thus, the reflection of signals mainly occurs at the bottom of the nighttime E region (Han and Cummer, 2010a and references therein). The $\mathrm{F}$ region is present both day and night; air density and recombination rate is very low in the region. Therefore, ionisation persists in the nighttime (also see Mimno, 1937; Poole, 1999; Prolss, 2004). In general, these layers are severely disturbed by phenomena of solar and geomagnetic origin, as well as planetary and tidal waves, thermospheric tides and stratospheric warming (Pancheva et al., 2008; Leonard et al., 2012; Chen et al., 2013; Goncharenko et al., 2012; Polyakova et al., 2014). However, effects at different heights, locations or latitudes vary in development, depending on time and intensity (of driving force). Ionospheric signature variations reflect different mechanisms and aspects of solar and other induced phenomena.

\subsection{VLF propagation in the Earth-ionosphere waveguide}

The velocity, direction and amplitude of most electromagnetic waves are distinctly affected when propagating through the ionosphere. This characteristics makes Radio waves one of the ideal tools for ionospheric study (Prolss, 2004). Very low frequency (VLF) radio waves in the $3-30 \mathrm{kHz}$ are effective in the investigation of solar induced variable conditions in the ionosphere (especially the D region) because their amplitude and phase are sensitive to changes in electrical conductivity of the lower ionosphere (Wait and Spies, 
1964; Mitra, 1974; Alfonsi et al., 2008). VLF radio signals are reflected alternately by the D region and the Earth's surface due to high conductivity (Mimno, 1937; Poole, 1999). The transmitted wave is thus guided between the Earth and the ionosphere enabling the signal to propagate globally through the Earth-Ionosphere waveguide. The signal is then received at various receivers across the world. Variations in daytime VLF signal amplitude and phase appear to be well correlated with solar X-ray output, with almost prompt responses. Hence, it has been used by many researchers to study sudden ionospheric disturbances and changes in the atmosphere (e.g., Araki, 1974; Hayakawa et al., 1996; Molchanov et al., 1998; Kleimenova et al., 2004; McRae and Thomson, 2004; Thomas et al., 2004; Chakrabarti et al., 2005; Grubor et al., 2005; Peter et al., 2006; Sasmal et al., 2009; Chakrabarti et al., 2010; Clilverd et al., 2010; Basak et al., 2011; Pal et al., 2012; Palit et al., 2013; Ray et al, 2013; Raulin et al., 2013; Nwankwo and Chakrabarti, 2014b). Other methods used for ionospheric studies include observational and experimental techniques and tools such as Global Navigation Satellite system (GNSS) receivers, vertical and oblique sounding, Riometers, incoherent scatter radars (e.g., EISCAT), coherent scatter radars (e.g., Goose Bay radar, SuperDARN), magnetometers, etc. (Greenwald et al., 1995, 1996; Honary et al., 1995; Lastovicka, 1996; Wild et al., 2003; Burke, 2000; Danilov and Lastovicka, 2001; Goldstein et al., 2005; Ruohoniemi and Greenwald, 2005; Alfonsi et al., 2008).

\subsection{VLF signal detection mechanism of sudden ionospheric disturbances}

The $\mathrm{D}$ region ionosphere is maintained by Lyman- $\alpha$ radiation at a wavelength of about $121.5 \mathrm{~nm}$, which ionises neutral nitric oxide (NO). With high solar activity, hard X-ray $(\lambda<1 \mathrm{~nm})$ may ionise $\mathrm{N}_{2}$ and $\mathrm{O}_{2}$. Galactic cosmic rays are also responsible for the ionisation of the lowest part of the lower ionosphere and the low-lying atmosphere down to the troposphere (also, see Mitra, 1974; Lastovika, 1996). A huge amount of energy is released during solar flare in the form of highly energetic ultraviolet radiation, mainly X-ray flux enhancement. The radiation penetrates the $\mathrm{D}$ region where it increases ionisation rate (of dominant neutral NO molecules), and enhances electron density. These processes enhance the 'thickness' of the D region, thereby decreasing the reflection height $(h)$ in the waveguide. This is normally detected as a sudden change (usually an increase) in the amplitude and phase enhancement of a VLF signal. VLF dusk-to-dawn signal exhibit high variability (or, fluctuation) during the night due to a significant fall in density 
of the $\mathrm{D}$ region. The signal is also sensitive to phenomena other than those originating from the Sun. Day time VLF signal is primarily controlled by the Sun.

\subsection{Geomagnetic induced variations of the ionosphere and effects}

Geomagnetic disturbances and storms are also known to produce significant global disturbances in the ionosphere, including the middle atmosphere and troposphere (Lastovika, 1996; Danilov and Lastovika 2001). Geomagnetic storms are the products of highly variable solar wind speeds and density and associated shock waves (Lastovika, 1986; Baker, 1996, 2000; Borovsky and Denton, 2006; Tsurutani et al., 2006; Kozyra et al., 2006). The effects of geomagnetic storms on the ionosphere manifest mainly through energetic particles precipitation, which lose their energy by impact and X-ray bremsstrahlung production (Lastovika, 1996). There is also a consequent and significant enhancement of electron density (Chenette et al., 1993; Stoker 1993; Lastovika, 1996), causing significant increase in radio wave absorption and subsequent disappearance of radio signals in MF/HF values (Lastovika, 1996). Galactic cosmic ray flux (which are modulated by geomagnetic storms) and global electric circuit and atmosphere electricity (affected by local changes of conductivity and ionosphere/magnetosphere electric fields and currents), are assumed to be the processes for ionospheric effects of geomagnetic storms (Danilov and Lastovika, 2001). VLF signals can be significantly affected by geomagnetic disturbances and storms induced ionosphere perturbations (Kikuchi and Evans, 1983). Nevertheless, a few researchers have used it to study these perturbations with insightful findings (e.g., Araki, 1974; Kleimenova et al., 2004; Peter et al., 2006; Clilverd et al., 2010; Kumar and Kumar, 2014; Tatsuta et al., 2015).

Apart from X-ray flux induced enhancement of amplitude and phase, anomalies in diurnal VLF signature may convey other important information, especially those related to geomagnetic disturbance or storm-induced ionospheric variations. If substantiated, such information could be instructive and resourceful to the study and understanding of the complex dynamics of Earth's ionosphere. Thus, in addition to well correlated VLF signal amplitude variation and phase enhancement with X-ray flux induced sudden ionospheric disturbances (SID), this work seeks to understand possible geomagnetic activity footprints in the $\mathrm{D}$ region of the ionosphere and their dependence on the propagation path of VLF radio waves. First, the analysis 
concentrates on four selected periods of significant solar and geomagnetic activities in order of increasing magnitude, followed by a detailed statistical analysis of up to 16 storm conditions.

\section{Data and method of analysis}

In this work, analysed data mainly include diurnal VLF signal amplitude (of up to three propagation paths) monitored at A118 SID monitoring station in Southern France (http://sidstation.loudet.org/data-en.xhtml), GOES solar X-ray flux, average z-components $\left(B_{z}\right)$ and total magnetic field $\left(H_{T}\right)$ (http://satdat.ngdc.noaa.gov/sem/goes/data/), global geomagnetic $A_{p}$ (NOAA) and disturbance storm time (Dst) index (from World Data Centre for Geomagnetism (WDCG)), solar wind speed $\left(V_{s w}\right)$ and particle density $(P D)$ (ftp://sohoftp.nascom.nasa.gov/sdb/goes/ace/). Analysis was conducted over four different 6-day periods with different geomagnetic conditions of varying disturbance. The space condition during 14th-19th February 2011 is recognised as moderately disturbed, the condition during 26th-31st May 2011 is recognised as a moderate storm, and condition during 24th-29th September and 23rd-28th October 2011 are recognised as relatively intense storm conditions. The choice of a six days time frame is to give us a reasonable time interval for analysis of data before, during and after the main event(s). The three propagation paths are shown in Figure 1 and include GQD-A118, ICV-A118, and DHO-A118; GQD (22.1 kHz GQD, lat N54.73 long $\left.\mathrm{W} 002.88^{\circ}\right)$, ICV $\left(20.27 \mathrm{kHz}\right.$, lat $\mathrm{N} 40.92^{\circ}$ long E009.73 $)$, DHO $(23.4$ $\mathrm{kHz}$, lat $\mathrm{N} 53.08^{\circ}$ long $\mathrm{W} 007.61^{\circ}$.

\subsection{Data description}

A solar flare is ranked based on its X-ray output, and classified according to the order of magnitude of the peak burst intensity (I), measured at the Earth in 0.1 to $0.8 \mathrm{~nm}$ band, $B=I<10^{-6} \mathrm{~W} / \mathrm{m}^{2}, C=10^{-6} \mathrm{I}<10^{-5} \mathrm{~W} / \mathrm{m}^{2}$, $M=10^{-5} \mathrm{I}<10^{-4} \mathrm{~W} / \mathrm{m}^{2}, X=10^{-4} \mathrm{IW} / \mathrm{m}^{2}$. We investigate solar wind speed conditions because the velocity, density, strength and direction of the solar wind plasma, and strength and direction of its associated magnetic field, influence the structure of the surrounding magnetic field of the Earth and controls the processes by which mass, momentum and energy are transferred from the solar wind to the Earth's magnetosphere-ionosphere system (Lastovika, 1989; Singer et al., 1996). The $B_{z}$ component significantly contributes to energy transfer from the solar wind sector to the magnetosphere (Prolss, 


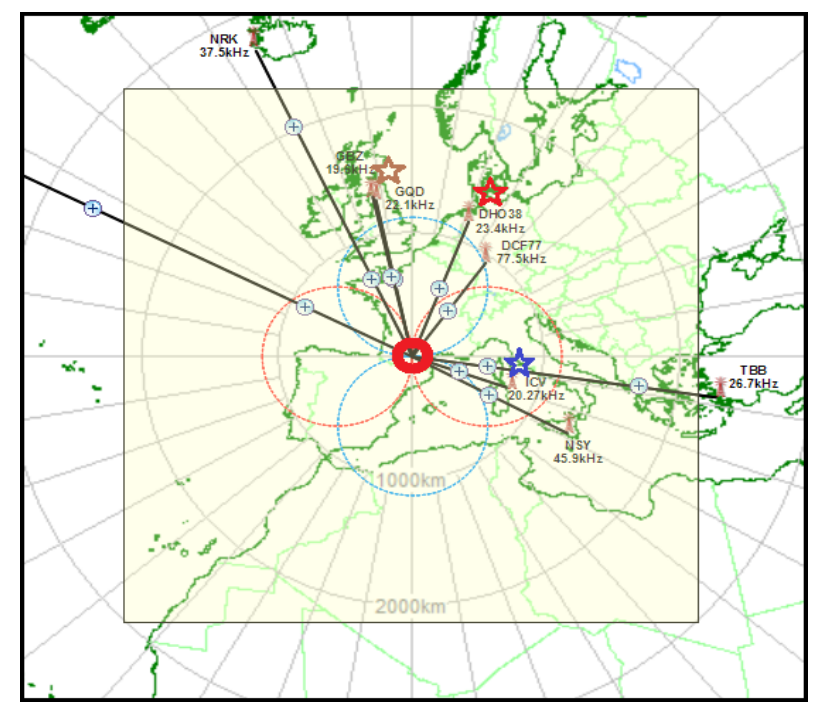

Figure 1: VLF signal propagation paths (PP) used in the study: A118 receiver (thick red circle), DHO transmitter (red star), GQD (brown star), ICV (blue star) [adopted from A118 SID station Web page]

2004). $H_{T}$ data can be used to deduce and check solar wind influence on the magnetosphere. Substorms advance and intensify current systems in the magnetosphere and ionosphere, which can also be detected via $H_{T}$ component. $A_{p}$ (or, $\left.K_{p}\right)$ are planetary indices and are the indicators of geomagnetic activity. The Dst is used to assess or measure the severity of magnetic storms. The strength of the surface magnetic field is inversely proportional to the energy content of the ring current, which increases during geomagnetic storms (Hamilton et al., 1988). The solar wind condition and the mentioned geomagnetic parameters are important for studying and understanding magnetosphere-ionosphere coupling and effects (Borovsky and Denton, 2006; Tsurutani et al., 2006; Kozyra et al., 2006; Weigel 2010; Nwankwo et al., 2014, 2015). However, having provided a precise background of the parameters, we will concentrate mainly on how various aspects of diurnal VLF signal varies in response to geomagnetic activity and storm footprints in the D region ionosphere via these parameters, especially the Dst index. Details of geomagnetic indices variation in response to solar wind conditions and sources can be found in some literatures e.g Lastovika (1989), Tsurutani et al. (1972, 1988, 1995, 1997, 2006, 2011), Baker (1996), Kozyra et al. (2006), 
Weigel (2010) and references therein.

We analyse 2- to 4-hour Mean VLF signal amplitude before 'local' sunrise and after sunset (hereafter respectively denoted as MBSR and MASS), and mid-day signal amplitude peak (MDP). We also identified variations in the so-called sunrise and sunset terminators (hereafter, denoted as SRT and SST). The aspects of a typical VLF signal (MBSR, MDP, MASS, SRT and SST) that were analysed are shown in Fig. 2 (a-d). In addition, daily solar flare count (for flares $\geq C$ ) and the standard deviation or fluctuation of daily Dst were calculated. The main goal of the analysis is to investigate the trend in variations of these components under given solar and geomagnetic induced space environmental conditions, for possible identification of geomagnetic footprint in D-region ionosphere via the propagation characteristics of VLF signal, in addition to known X-ray flux induced prompt response of VLF amplitude and phase. Data were analysed for two signal propagation paths (PP) in each case. To begin with, we perform a detailed study of four particular cases, and then investigate the statistical significance of our results with more cases (up to 16).

\section{Results and Discussion}

Figure 3(a-h) shows diurnal VLF amplitude for GQD-A118 and ICVA118 propagation paths, X-ray flux output, solar wind speed $\left(V_{s w}\right)$, particle density (PD), $B_{z}$ magnetic field component, $H_{T}$ magnetic field, daily Dst standard deviation and $A_{p}$ variation during 14th-19th February 2011. The period is associated with high flare activity (up to 79 flares; $\mathrm{C}=69, \mathrm{M}=9$, $\mathrm{X}=1$ ) and Dst variations of $>-50$ (also see, Table 1). High flare events were observed on 14th, 16th and 18th (Fig. 3c), as well as significant geomagnetic activity on the 14th and 18th February (Fig. 3e-g). Highly variable solar wind speed $\left(V_{s w}\right)$ and associated magnetospheric impact (via $B_{z}$ and $H_{T}$ ) were also observed from 06:00 pm, 14th - 12:00 noon, 15th and during most part of 18th February (Fig. 3d-f). The extent and severity of induced magnetospheric perturbations is highlighted by the Dst during late 14th and the considerable part of 18th (Fig. 3g). High $A_{p}$ index of 18th February is therefore not surprising (Fig. 2h). VLF signal amplitude of the two propagation paths responded in a manner consistent with high flare events during the period. However, the flare-induced perturbations are distinct in VLF signals (during local daytime), and appear to overshadow those of geomagnetic 

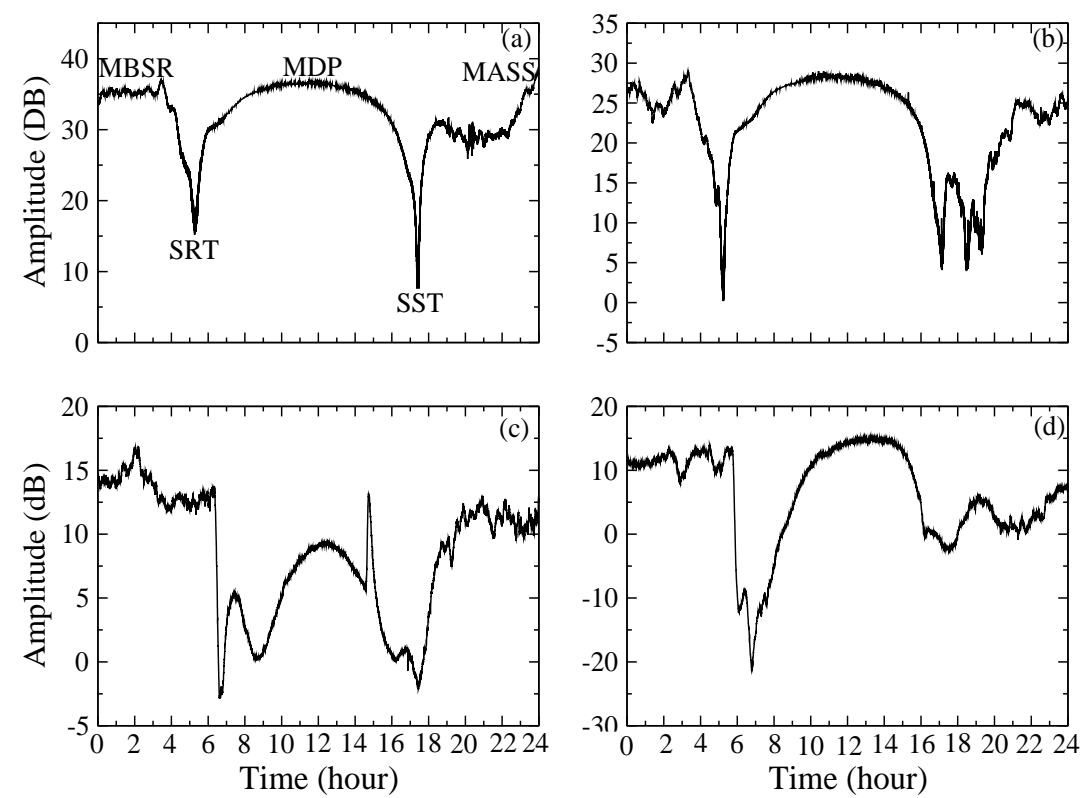

Figure 2: Diurnal signature of VLF signals from propagation paths showing various aspects as identified in (a). 


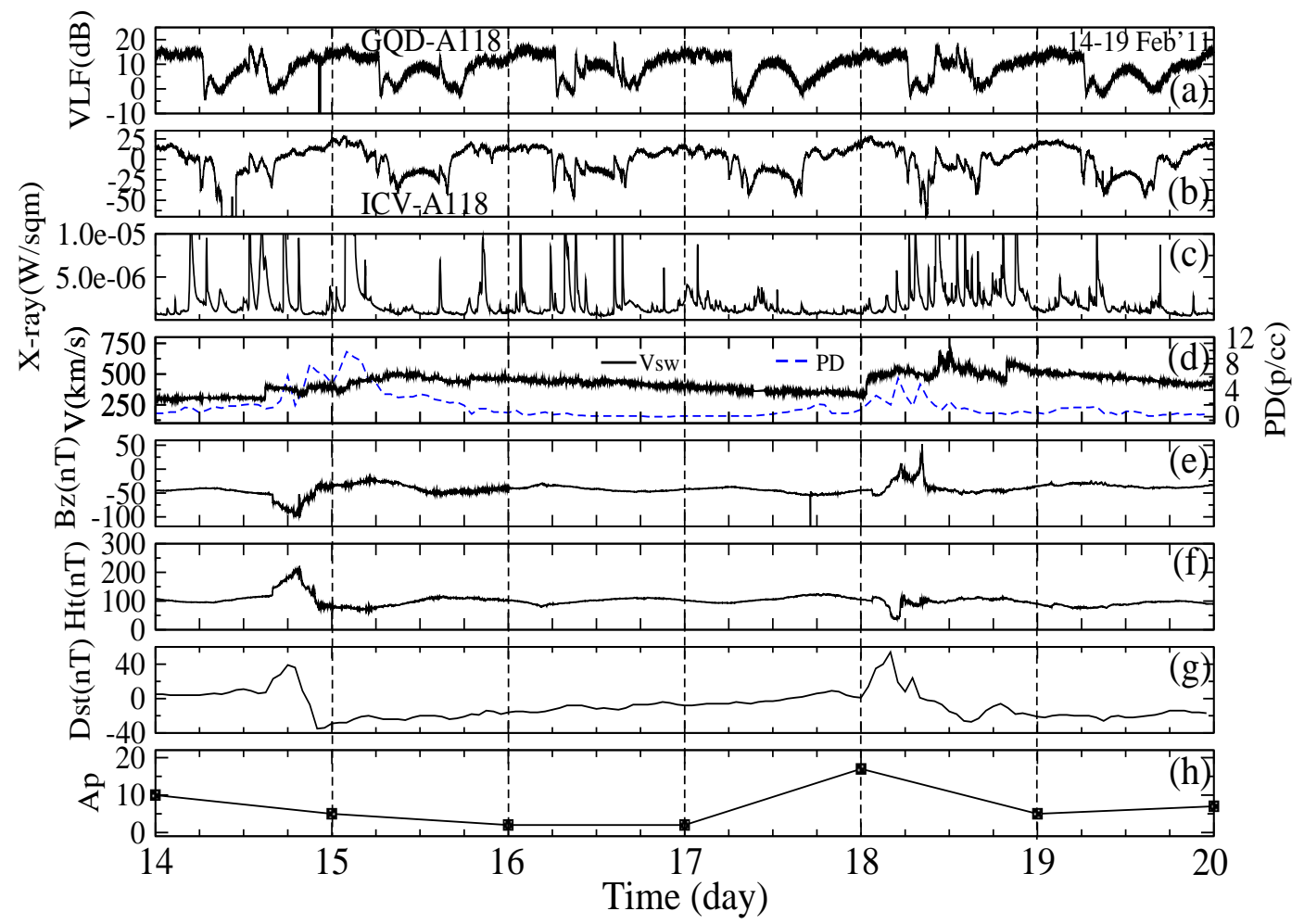

Figure 3: (a) Diurnal VLF amplitude for GQD-A118 PP; (b) VLF amplitude for ICVA118 PP; (c) X-ray flux output; (d) solar wind speed $\left(V_{s w}\right)$ and particle density $(P D)$; (d) $B_{z}$ magnetic field component; (e) $H_{T}$ magnetic field; (f) Dst and (g) $A_{p}$ variations during 14-19th February 2011.

activity origin. We therefore looked for the trend in the signal diurnal variations such as MBSR, MDP, MASS, SST and SRT, for possible separation of distinct signatures of geomagnetic disturbance induced variations.

Figure 4 shows daily Dst standard deviation, 4-hour mean signal amplitude before local sunrise (MBSR), mid-day signal peak (MDP), 4-hour mean signal amplitude after sunset (MASS), variation in sunrise terminator (SRT) and in sunset terminator (SST) for (a) GQD-A118 and (b) ICV-A118 propagation paths during 14-19th February 2011. A summary of relative trend in variations of the parameters over the period is provided in Table 1 . Two main geomagnetic disturbed days are the 14th (day 1 ) and the 18th (day 5) 
presumably due to increase or spikes in solar wind speed $\left(V_{s w}\right)$ and particle density $(P D)$ (see, Fig. 3d). Proper analysis of a trend on a particular day requires a comparison with the trend of the previous day and the day after the event, because of the varying timescale of ionospheric response to different aspects of solar forcing and mechanisms. Therefore, we consider the trend of pre-event day in order to determine that of the event (s) day, and also consider the post-event(s) day for extended effect. We observed an increase in MBSR and SRT, but 'dipping' of MDP, MASS and SST on 15th (day 2) (Fig. 4a). Note the onset of perturbations on the 14th (day 1) - during and after sunset. The influence of the induced perturbations are therefore expected to extend into a considerable part of 15 th (day 2). There was a quiet geomagnetic condition on the 16th (day 3), and almost all the parameters increased. Of interest is the more (and longer) geomagnetic disturbed condition on the 18th (day 5). Only the SST increased (during which a decline in the initial induced perturbation was expected), while almost all other parameters (MBSR, MDP, MASS and SRT) experienced a 'dipping'. The observed trend is replicated in ICV-A118 propagation path around 15th (day 2) but quite inconsistent on 18th (day 5) - mainly increase of MBSR, MDP and MASS, but dipping of SRT and SST (Fig 4b). However, the increase in MDP appeared to be related to flare induced signal amplitude variation on the signal as well as high fluctuation in ICV-A118 propagation path signal level, before and after sunset (see, Fig 3b).

Figure 5 shows the diurnal VLF signal amplitude variations for GQDA118 and ICV-A118 propagation paths, X-ray flux, $V_{s w}, P D, B_{z}, H_{T}$, daily Dst standard deviation and $A_{p}$ variations during 26th-31st May 2011. Blue and red lines in the Figure indicate the storm commencement and peak time, respectively. The period is associated with moderate flare activity (up to 43; $\mathrm{C}=41, \mathrm{M}=2, \mathrm{X}=0$ ), as well as a moderate storm condition (Dst <-50 (up to -91). The most disturbed days in this case are the 28 th and the 29 th May, following a geomagnetic storm on the 28th (Fig. 5(c-h)). The geomagnetic storm of 28th February appears to be related to the sudden (and significant) rise in $V_{s w}$ and $P D$, possibly of coronal origin. Up to three CMEs with the speed exceeding $1000 \mathrm{~km} / \mathrm{s}$ occurred between 27th and 29th (http: //cdaw.gsfc.nasa.gov/CME_list/UNIVERSAL/2011_05/univ2011_05.html). Solar wind density influences the capability of a given value of the solar wind electric field (SWEF) to create a Dst disturbance or geo-efficiency (Weigel, 2010; Tsurutani et al., 2011; Nwankwo et al., 2016). Also, solar flares and 

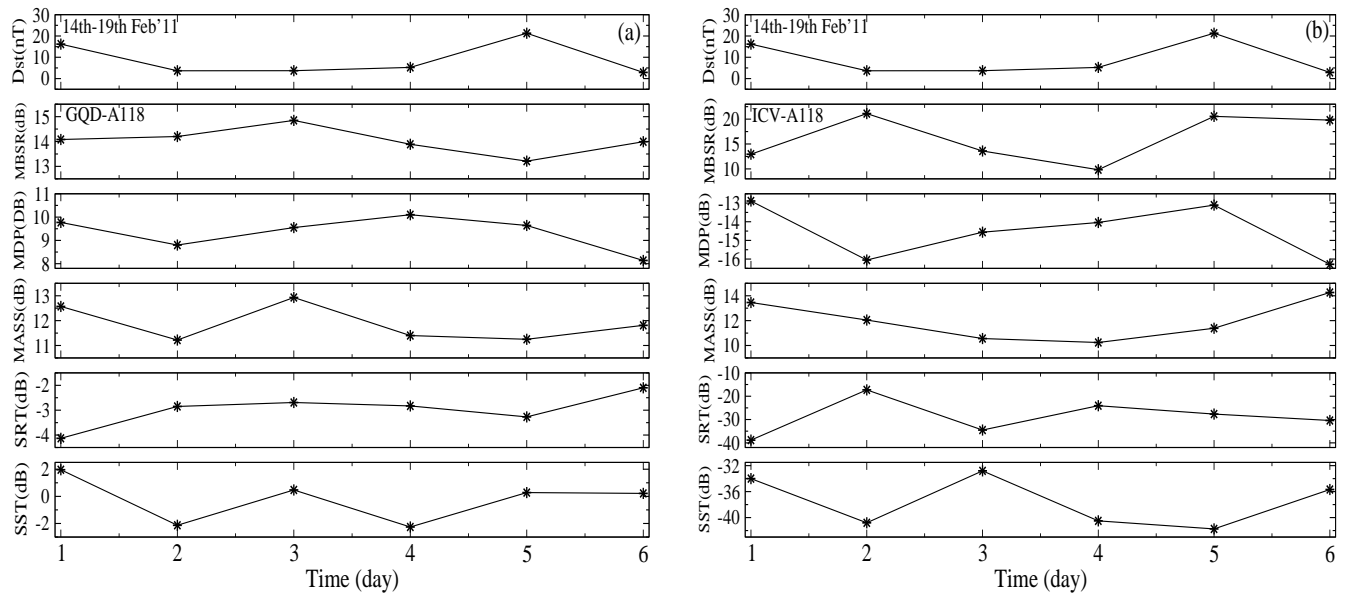

Figure 4: Daily Dst standard deviation, 4-hour mean signal amplitude before sunrise (MBSR), mid-day signal peak (MDP), 4-hour mean signal amplitude after sunset (MASS), sunrise terminator (SRT) and sunset terminator (SST) variations for (a) GQD-A118 and (b) ICV-A118 propagation path during 14-19th February 2011.

prominence eruptions are known independent and sporadic events, but they do also occur in association with coronal mass ejections (CMEs). However, we do not strictly attribute the solar wind and magnetosphere conditions during this period to CMEs because of limited scope of our analysis in this regard. In Fig. 5(a-c), we observed that with relatively high flare activity around 28th-29th May, the known diurnal (daytime) signal amplitude-spike in response to solar X-ray output in both propagation paths tend to be diminished under geomagnetic storm condition when compared with 14th-19th February scenario (Fig. 5a-b). This situation is replicated in the other three storm conditions investigated alongside.

Figure 6 shows daily Dst standard deviation, 2-hour mean MBSR, MDP, 2-hour mean MASS, SRT and SST variations for (a) GQD-A118 and (b) ICV-A118 propagation paths during 26th-31st May 2011. A summary of trend in variation of the parameters over the period is provided in Table 2. Our main focus here is on 28th (day 3), being the most disturbed, as well as the storm day. We observed an increase in MBSR, MDP and MASS, but a dipping of SRT and SST in GQD-A118 propagation path (Fig. 6a). Notwithstanding, dipping of the MBSR and MDP occurred on the day following the 


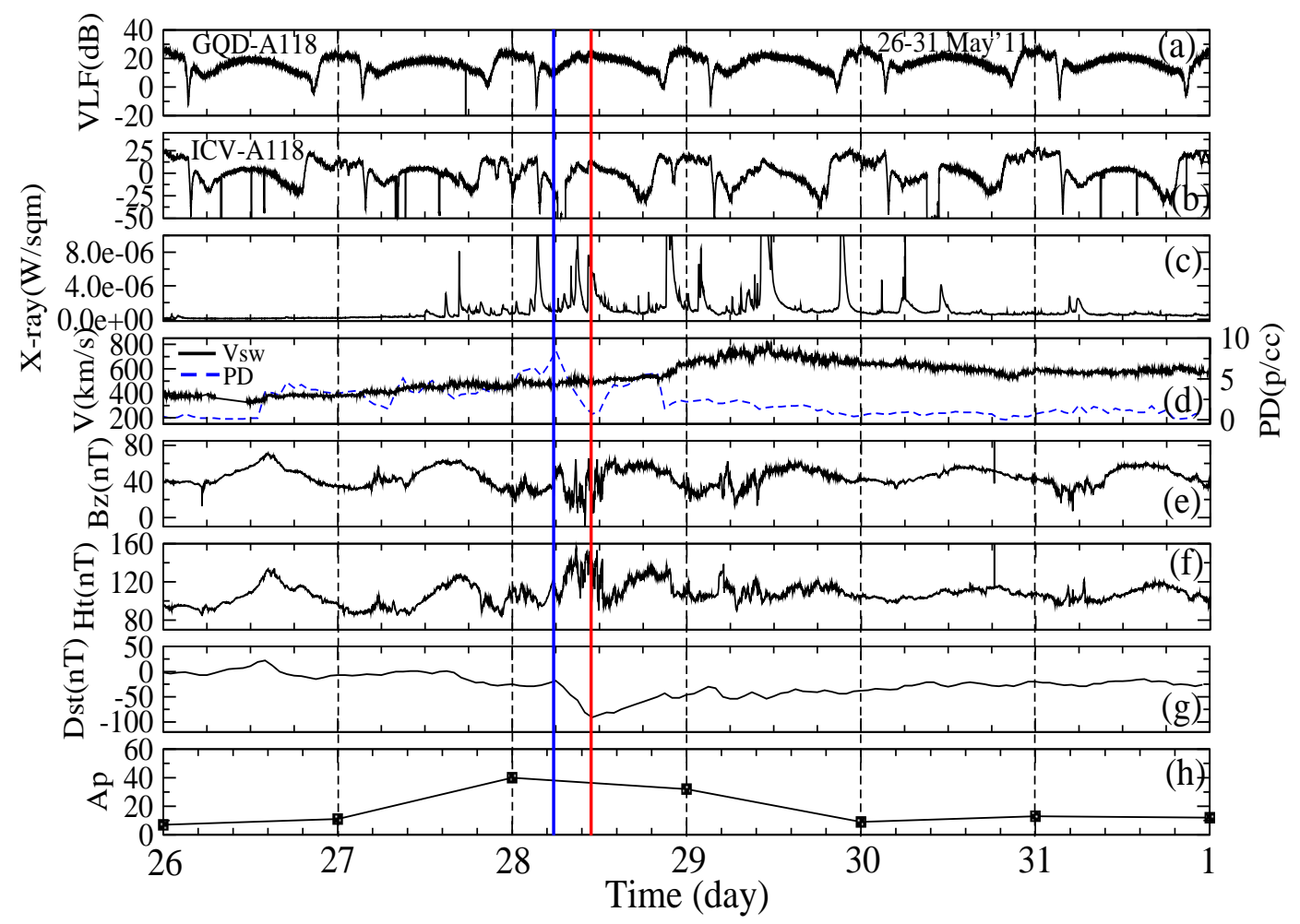

Figure 5: (a) Diurnal VLF amplitude for GQD-A118 PP; (b) VLF amplitude for ICVA118 PP; (c) X-ray flux output; (d) solar wind speed $\left(V_{s w}\right)$ and particle density $(P D)$; (d) $B_{z}$ magnetic field component; (e) $H_{T}$ magnetic field; (f) Dst and (g) $A_{p}$ variations during 26th-31st May 2011 (Blue and red lines in the Figure indicate storm commencement and peak time respectively) 
Table 1: Trend of time variation of VLF amplitude, Dst and flare count during 15-18th February 2011 for GQD-A118 and ICV-A118 propagation path

\begin{tabular}{|c|c|c|c|c|c|c|c|c|}
\hline \multicolumn{9}{|c|}{ GQD-A118 propagation path } \\
\hline Date & \multicolumn{3}{|c|}{ Mean Signal peak (dB) } & \multicolumn{2}{|c|}{ Signal dip $(\mathrm{dB})$} & Dst (nT) & \multicolumn{2}{|c|}{ Flare count } \\
\hline & MBSR & MDP & MASS & SRT & SST & $\sigma_{D s t}$ & $\geq C$ & C M X \\
\hline $14 / 2 / 11$ & $14.08 \pm 0.78$ & 9.77 & $12.57 \pm 2.18$ & -4.13 & 1.96 & \pm 16.19 & 12 & 1110 \\
\hline $15 / 2 / 11$ & $14.20 \pm 1.15$ & 8.80 & $11.22 \pm 0.72$ & -2.85 & -2.13 & \pm 3.67 & 8 & 701 \\
\hline $16 / 2 / 11$ & $14.85 \pm 1.07$ & 9.55 & $12.93 \pm 0.95$ & -2.69 & 0.47 & \pm 3.71 & 15 & 1230 \\
\hline $17 / 2 / 11$ & $13.89 \pm 1.14$ & 10.10 & $11.40 \pm 0.82$ & -2.83 & -2.26 & \pm 5.27 & 12 & 1200 \\
\hline $18 / 2 / 11$ & $13.21 \pm 0.90$ & 9.64 & $11.25 \pm 1.09$ & -3.27 & 0.28 & \pm 21.29 & 20 & 1550 \\
\hline $19 / 2 / 11$ & $13.99 \pm 1.10$ & 8.14 & $11.81 \pm 2.23$ & -2.10 & 0.22 & \pm 2.90 & 12 & 1200 \\
\hline \multicolumn{9}{|c|}{ ICV-A118 propagation path } \\
\hline $\begin{array}{ll}14 / 2 / 11 \\
\end{array}$ & $12.95 \pm 3.82$ & -12.89 & $13.46 \pm 3.40$ & -38.82 & $\begin{array}{l}-33.99 \\
\end{array}$ & \pm 16.19 & 12 & 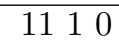 \\
\hline $15 / 2 / 11$ & $21.11 \pm 3.11$ & -16.05 & $12.05 \pm 4.17$ & -17.30 & -40.80 & \pm 3.67 & 8 & 701 \\
\hline $16 / 2 / 11$ & $13.60 \pm 2.38$ & -14.56 & $10.56 \pm 3.49$ & -34.52 & -32.80 & \pm 3.71 & 15 & 1230 \\
\hline $17 / 2 / 11$ & $9.83 \pm 3.81$ & -14.04 & $10.24 \pm 2.57$ & -24.08 & -40.50 & \pm 5.27 & 12 & 1200 \\
\hline $18 / 2 / 11$ & $20.56 \pm 3.24$ & -13.11 & $11.39 \pm 3.95$ & -27.65 & -41.75 & \pm 21.29 & 20 & 1550 \\
\hline $19 / 2 / 11$ & $19.81 \pm 1.25$ & -16.28 & $14.26 \pm 3.88$ & -30.42 & -35.67 & \pm 2.90 & 12 & 1200 \\
\hline
\end{tabular}

storm day (moderate but significantly disturbed 29th (day 2)). In ICV-A118 propagation path, the MASS increased slightly while MBSR, MDP, SRT and SST dipped with high Dst (Fig. 6b). It is important to note that we had to take a two hour mean due to increase in day length. Also note the spike in MDP due to the possible influence of the flare particularly in GQD-A118 propagation path on 28th (dipping need to be large or significant to nullify flare-induced influence). Understandably, geomagnetic effects are also not expected on any portion of the signal (e.g., MBSR, MDP, MASS, SRT, SST) before significant geomagnetic perturbations. The increase (MDP) could also be due to the propagation characteristics of ICV-A118 propagation path, because mode interference significantly depends on ionospheric conditions at the time, propagation paths and energetic electron precipitation level on the ionosphere due to the magnetic storm, which depends on geomagnetic latitude (Tatsuta et al., 2015).

Figure 7 shows the diurnal VLF amplitude variations for GQD-A118 and DHO-A118 propagation paths, X-ray flux, $V_{s w}, P D, B_{z}, H_{T}$, daily Dst standard deviation and $A_{p}$ variations during 24th-29th September 2011. The 

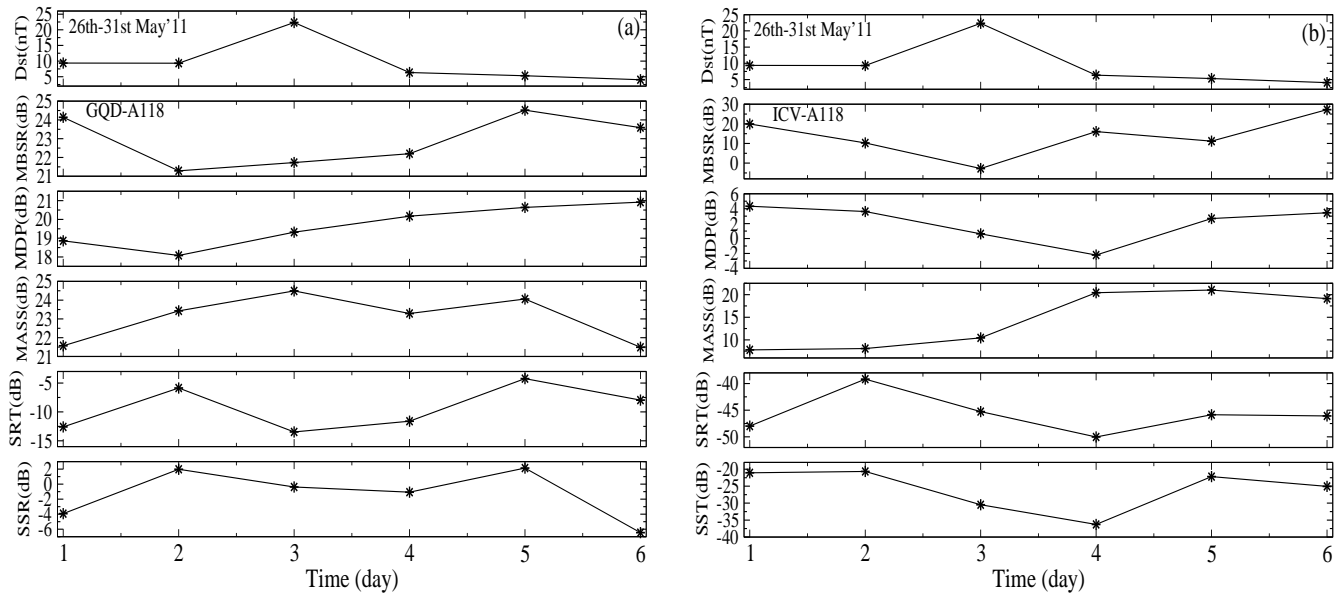

Figure 6: Daily Dst standard deviation, two-hour mean signal amplitude before sunrise (MBSR), mid-day signal peak (MDP), two-hour mean signal amplitude after sunset (MASS), sunrise terminator (SRT) and sunset terminator (SST) variations for (a) GQDA118 and (b) ICV-A118 propagation path during 26th-31st May 2011.

period is associated with relatively high flare events (up to $51 ; \mathrm{C}=33, \mathrm{M}=17$, $\mathrm{X}=1$ ) and intense storm conditions with Dst $\leq-100$. The unique feature of the period is the associated sub-storm of late 26th (red line) following the storm condition that commenced before noon with peak (broken red line), which also marked the sub-storm commencement (Fig. 7e-g). Milder storm conditions also occurred on 28th and 29th. The storm-driving high variable solar wind (and PD spike) is clearly observed in Fig. 6d. Dipping of DHOA118 propagation path daytime (and MDP) signal on 26th is clearly visible in Fig. 7b, with the post storm day signal (with lesser geomagnetic indices and/or disturbances) on 27th exhibiting a tendency of recovery (or return) to pre-storm level. The trend of variations of MBSR, MDP, MASS, SRT and SST have also shown similar tendency.

Figure 8 shows daily Dst standard deviation, 4-hour mean MBSR, MDP, 4-hour mean MASS, SRT and SST variations for (a) GQD-A118 and (b) DHO-A118 propagation paths during 24th-29th September 2011. Summary of the trend in variation of the parameters over the period is provided in Table 3. In GQD-A118 propagation path signal, dipping of MDP, SRT and SST were observed on 26th (day 3), while MBSR and MASS increased (Fig. 


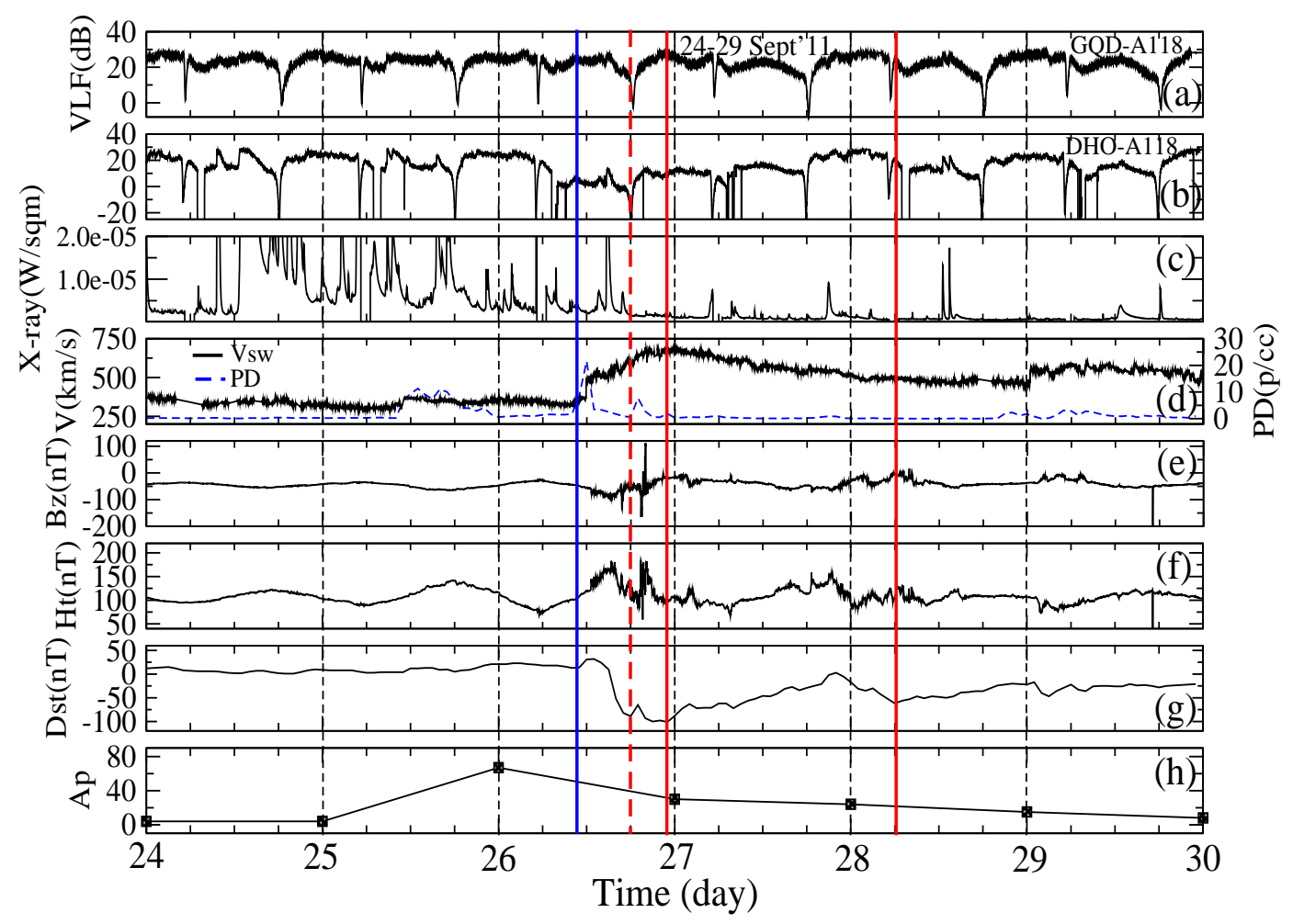

Figure 7: (a) Diurnal VLF amplitude for GQD-A118 PP (b) Diurnal VLF amplitude for DHO-A118 PP (c) X-ray flux output (d) solar wind speed $\left(V_{s w}\right)$ and particle density $(P D)$ (d) $B_{z}$ magnetic field component (e) $H_{T}$ magnetic field (f) Dst and (g) $A_{p}$ variations during 24th-29th September 2011 (Blue and red lines in the Figure indicate storm commencement and peak time respectively) 
Table 2: Trend of time variation of VLF amplitude, Dst standard deviation and flare count during 26-31st May 2011 for GQD-A118 and ICV-A118 propagation path.

\begin{tabular}{|c|c|c|c|c|c|c|c|c|}
\hline \multicolumn{9}{|c|}{ GQD-A118 propagation path } \\
\hline Date & \multicolumn{3}{|c|}{ Mean Signal peak $(\mathrm{dB})$} & \multicolumn{2}{|c|}{ Signal dip $(\mathrm{dB})$} & Dst (nT) & \multicolumn{2}{|c|}{ Flare count } \\
\hline & BSR & Mid-day & ASS & SRT & SST & $\sigma_{D s t}$ & $\geq C$ & C M X \\
\hline $26 / 5 / 11$ & $24.14 \pm 1.24$ & 18.86 & $21.57 \pm 1.01$ & -12.59 & -3.93 & \pm 9.37 & 0 & $\begin{array}{llll}0 & 0 & 0\end{array}$ \\
\hline $27 / 5 / 11$ & $21.29 \pm 1.05$ & 18.08 & $23.43 \pm 0.65$ & -5.86 & 1.98 & \pm 9.31 & 5 & 500 \\
\hline $28 / 5 / 11$ & $21.73 \pm 1.00$ & 19.32 & $24.49 \pm 1.22$ & -13.47 & -0.38 & \pm 22.33 & 19 & 1810 \\
\hline $29 / 5 / 11$ & $22.20 \pm 1.42$ & 20.17 & $23.29 \pm 1.63$ & -11.60 & -1.07 & \pm 6.35 & 13 & 1210 \\
\hline $30 / 5 / 11$ & $24.52 \pm 1.74$ & 20.64 & $24.06 \pm 1.07$ & -4.24 & 2.14 & \pm 5.31 & 4 & 400 \\
\hline $31 / 5 / 11$ & $23.59 \pm 2.14$ & 20.92 & $19.11 \pm 4.10$ & -7.75 & -6.46 & \pm 4.04 & 2 & 200 \\
\hline \multicolumn{9}{|c|}{ ICV-A118 propagation path } \\
\hline $26 / 5 / 11$ & $19.92 \pm 4.32$ & 4.33 & $7.79 \pm 2.62$ & -47.18 & -21.05 & \pm 9.37 & 0 & $\begin{array}{llll}0 & 0 & 0\end{array}$ \\
\hline $27 / 5 / 11$ & $10.26 \pm 4.32$ & 3.62 & $8.08 \pm 8.74$ & -39.18 & -20.66 & \pm 9.31 & 5 & 500 \\
\hline $28 / 5 / 11$ & $-2.74 \pm 8.39$ & 0.63 & $10.44 \pm 9.05$ & -45.27 & -30.47 & \pm 22.33 & 19 & 1810 \\
\hline $29 / 5 / 11$ & $16.07 \pm 2.28$ & -2.21 & $20.42 \pm 3.17$ & -50.02 & -36.28 & \pm 6.35 & 13 & 1210 \\
\hline $30 / 5 / 11$ & $11.19 \pm 2.94$ & 2.68 & $21.02 \pm 3.28$ & -45.85 & -22.17 & \pm 5.31 & 4 & 400 \\
\hline $31 / 5 / 11$ & $22.21 \pm 3.83$ & 3.45 & $19.11 \pm 4.10$ & -46.08 & -25.07 & \pm 4.04 & 2 & 200 \\
\hline
\end{tabular}

8a). It is important to note that the peak of the geomagnetic storms-induced perturbations on the ionosphere, which commenced during the later part of 26th are expected into greater part of 27th. As could be seen in Fig. $7 \mathrm{~g}$, the Dst recovery during 27th is associated with momentary perturbations, followed by the sub-storm commencement at 06:00 pm on that day. Further dippings of MBSR, MDP, MASS and SST were also observed on 27th (day 4; see Fig 8a). Thereafter, the MBSR, MDP and MASS increased with reduced Dst on the 28th. Notwithstanding, storm conditions were also recorded on the 28th and 29th, the perturbations are not comparable to those of 26th27th. In DHO-A118 propagation path, dipping of the MDP, MASS and SST were observed on the 26th (day 3) and 28th (day 4; see Fig 8b). On the other hand, there is a relative increase in MBSR and SRT on the days (3 and 4). While the trends in the two propagation paths appear to significantly reflect the space weather conditions, the dipping or increase of the signal varied.

Figure 9 shows the diurnal VLF amplitude variations for GQD-A118 and DHO-A118 propagation paths, X-ray flux, $V_{s w}, P D, B_{z}, H_{T}$, daily Dst standard deviation and $A_{p}$ variations during 23rd-28th October 2011. This period 

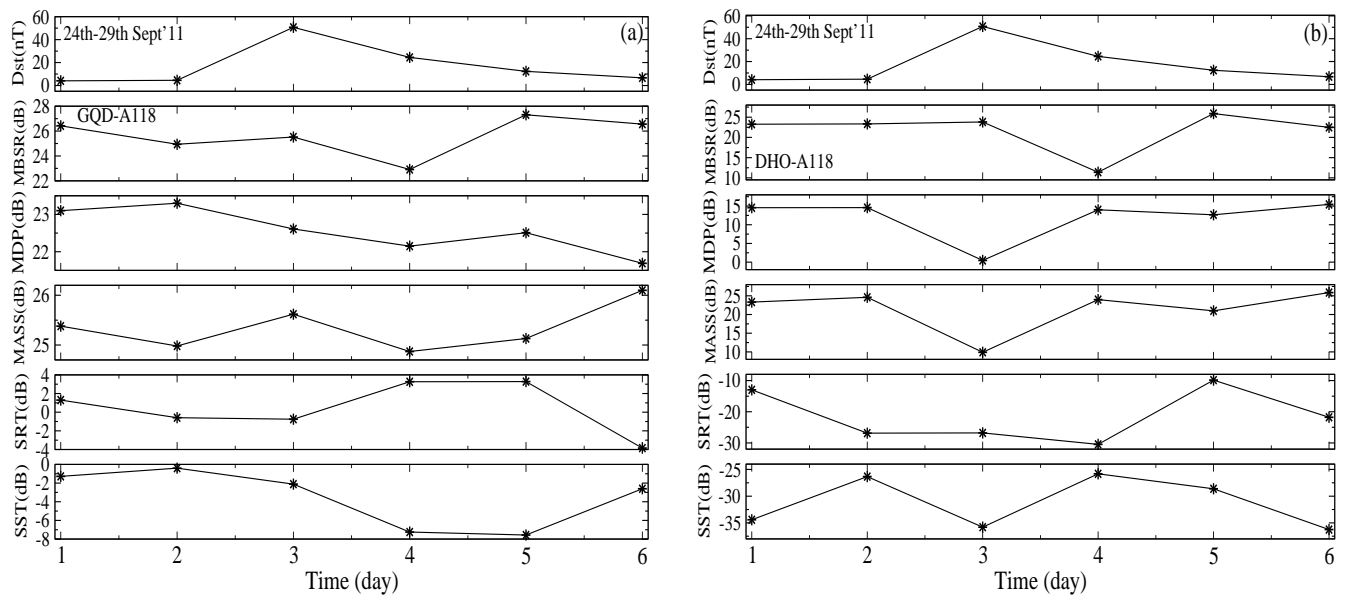

Figure 8: Daily Dst standard deviation, 4-hour mean signal amplitude before sunrise (MBSR), mid-day signal peak (MDP), 4-hour mean signal amplitude after sunset (MASS), sunrise terminator (SRT) and sunset terminator (SST) variations for (a) GQD-A118 and (b) DHO-A118 propagation path during 24th-29th September 2011.

is associated with relatively low flare activity (only $11 \mathrm{C}$ class flares), but with an intense storm condition of higher magnitude (Dst $<-100$ (down to 132)). The storm occurred in the early hours of 25th, which commenced late 24th (around 06:00 pm), presumably due to high speed solar wind (HSS) and $P D$ condition of 24th October (Fig 9d-h). VLF signal data for GQDA118 propagation path during 12:00 noon, 25th - 06:00 pm, 26th October (Fig. 9a) are not available. It is worth mentioning that only DHO-A118 propagation path (at A118 SID receiving station) recorded data during this time interval. Data of about 6 other propagation paths (e.g., GBZ-A118, ICV-A118, NAA-A118, TBB-A118) in the series are also not available (see, Fig. 1 for PP identification). As this time interval probably corresponds to the peak period of induced ionosphere perturbations, it will be interesting to further investigate possible cause of the scenario (beyond the scope of this work), with respect to the prevailing geomagnetic condition. Again, dipping of DHO-A118 propagation path daytime and MDP signal on 25th (most disturbed day) is clearly visible (Fig. 9b), with the post storm day signal exhibiting a drop or recovery to pre-storm level.

Figure 10 shows daily Dst standard deviation, 4-hour mean MBSR, MDP, 


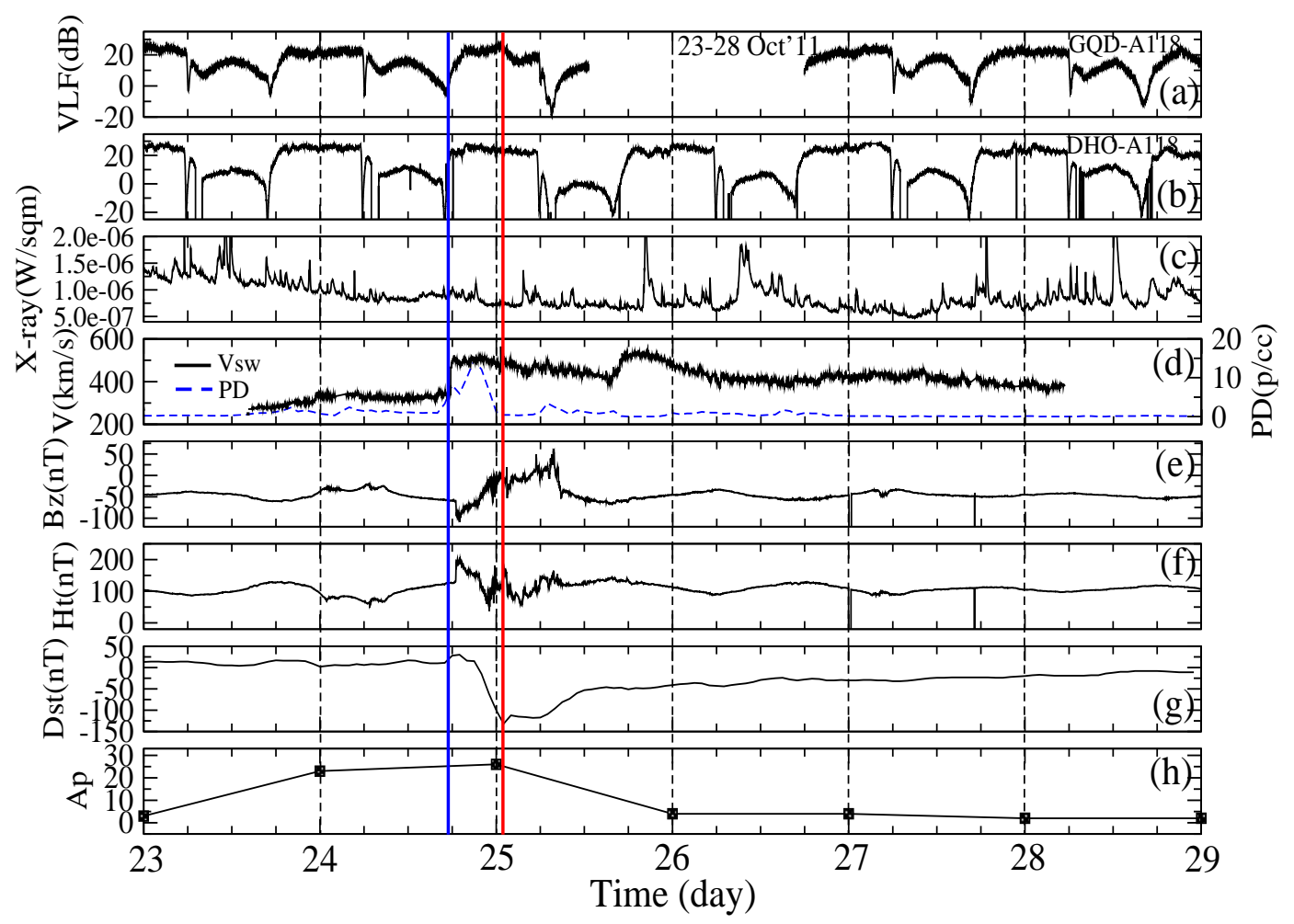

Figure 9: (a) Diurnal VLF amplitude for GQD-A118 PP (b) Diurnal VLF amplitude for DHO-A118 PP (c) X-ray flux output (d) solar wind speed (d) $B_{z}$ magnetic field component (e) $H_{T}$ magnetic field (f) Dst and (g) $A_{p}$ variations during 23rd-28th October 2011 
Table 3: Trend of time variation of VLF amplitude, Dst and flare count during 25th-28th September 2011 for GQD-A118 and DHO-A118 propagation path.

\begin{tabular}{|c|c|c|c|c|c|c|c|c|}
\hline \multicolumn{9}{|c|}{ GQD-A118 propagation path } \\
\hline Date & \multicolumn{3}{|c|}{ Mean Signal peak $(\mathrm{dB})$} & \multicolumn{2}{|c|}{ Signal dip $(\mathrm{dB})$} & Dst (nT) & \multicolumn{2}{|c|}{ Flare count } \\
\hline & BSR & Mid-day & ASS & SRT & SST & $\sigma_{D s t}$ & $\geq C$ & C M X \\
\hline $24 / 9 / 11$ & $26.42 \pm 1.02$ & 23.10 & $25.38 \pm 2.10$ & 1.30 & -1.28 & \pm 4.08 & 13 & 481 \\
\hline $25 / 9 / 11$ & $24.94 \pm 1.16$ & 23.30 & $24.98 \pm 0.96$ & -0.59 & -0.40 & \pm 4.56 & 10 & 460 \\
\hline $26 / 9 / 11$ & $25.52 \pm 1.14$ & 22.61 & $25.62 \pm 1.59$ & -0.75 & -2.11 & \pm 50.73 & 11 & 920 \\
\hline $27 / 9 / 11$ & $22.91 \pm 1.35$ & 22.15 & $24.87 \pm 1.63$ & -3.26 & -7.25 & \pm 24.54 & 8 & 800 \\
\hline $28 / 9 / 11$ & $27.31 \pm 0.77$ & 22.51 & $25.13 \pm 1.38$ & 3.28 & -7.57 & \pm 12.37 & 4 & 310 \\
\hline $29 / 9 / 11$ & $26.56 \pm 1.29$ & 21.69 & $26.10 \pm 2.32$ & -3.85 & -2.61 & \pm 6.73 & 3 & 300 \\
\hline \multicolumn{9}{|c|}{ DHO-A118 propagation path } \\
\hline $24 / 9 / 11$ & $23.26 \pm 2.04$ & 14.55 & $23.32 \pm 1.00$ & -12.96 & -34.41 & \pm 4.08 & 13 & 481 \\
\hline $25 / 9 / 11$ & $23.33 \pm 1.29$ & 14.57 & $24.60 \pm 0.99$ & -26.86 & -26.34 & \pm 4.56 & 10 & 460 \\
\hline $26 / 9 / 11$ & $23.81 \pm 1.05$ & 0.45 & $9.90 \pm 1.48$ & -26.79 & -35.80 & \pm 50.73 & 11 & 920 \\
\hline $27 / 9 / 11$ & $11.38 \pm 1.05$ & 14.00 & $23.68 \pm 1.90$ & -30.47 & -25.82 & \pm 24.54 & 8 & 800 \\
\hline $28 / 9 / 11$ & $25.90 \pm 1.74$ & 12.66 & $20.98 \pm 2.09$ & -9.85 & -28.62 & \pm 12.37 & 4 & 310 \\
\hline $29 / 9 / 11$ & $22.49 \pm 2.04$ & 15.43 & $25.87 \pm 3.31$ & -21.78 & -36.25 & \pm 6.73 & 3 & 300 \\
\hline
\end{tabular}

4-hour mean MASS, SRT and SST variations for (a) GQD-A118 and (b) DHO-A118 propagation paths during 23rd-28th October 2011. Summary of trend in variation of the parameters over the period is provided in Table 4. GQD-A118 propagation path data during 25th and 26th is inadequate for the present analysis (Fig. 10a). The DHO-A118 propagation path signal showed dipping of the MBSR, MDP and MASS on 25th (day 3), corresponding to the storm's peak day, but an increase in SRT and SST (Fig 10a). The prevailing space weather conditions (with peak) of 25th (day 3) commenced at around 06:00 pm on 24th (day 2). Interestingly, dipping of the MDP and MASS also commenced on 24th (day 2). There is a post-storm day increase of MBSR, MDP and MASS with significant Dst low on 26th, a scenario that is characteristic of most post-storm day signals. We, therefore viewed such scenario as post-storm day signal recovery tendency.

We now identify the most disturbed day in each of the four periods, and analyse the trend in the signal metrics variation on the day, namely, event 1 $\left(E_{1}\right)$ on 18th February, 2011; event $2\left(E_{2}\right)$ on 28th May, 2011; event $3\left(E_{3}\right)$ on 26-27 September, 2011; and event $4\left(E_{4}\right)$ on 25th October 2011. Due to 

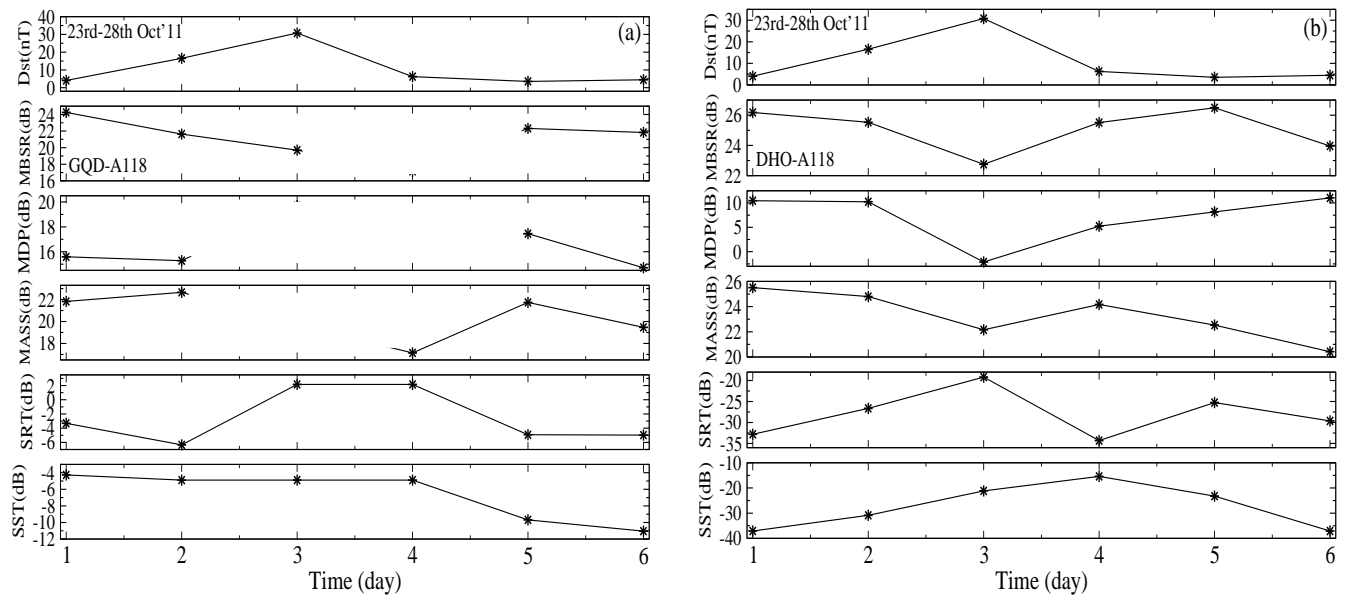

Figure 10: Daily Dst standard deviation, 4-hour mean signal amplitude before sunrise (MBSR), mid-day signal peak (MDP), 4-hour mean signal amplitude after sunset (MASS), sunrise terminator (SRT) and sunset terminator (SST) variations for (a) GQD-A118 and (b) DHO-A118 propagation path during 23rd-28th October 2011.

the peculiarity of the events during 26th-27th September, 2011 (recurrent substorm), two days have been allowed for the analysis. In general, two of three events $\left(E_{1-3}\right)$ showed dipping of MDP in GQD-A118 propagation path (VLF data during $E_{4}$ is not available). Three of the four events $\left(E_{1-4}\right)$ showed dipping of MDP in ICV/DHO-A118 propagation paths. We note that solar flare occurred around mid-day in the days when MDP showed no dipping. This suggests possible flare induced increase of signal amplitude on the MDP or resulting from other atmospheric phenomena. Two of four events $\left(E_{1-4}\right)$ showed dipping of MBSR in GQD-A118 propagation path, and dipping in all the four events in ICV/DHO-A118 propagation paths. Two of three events $\left(E_{1-3}\right)$ showed dipping of MASS in GQD-A118 propagation path (VLF data during $E_{4}$ is not available), and two of the four events in ICV/DHO-A118 propagation path. Three of the four events showed dipping of SRT in GQD-A118 propagation path, and two of the four in ICV/DHOA118 propagation paths. Two of the four events showed dipping of SST in GQD-A118 propagation path, and three of the four in ICV/DHO-A118 propagation paths. We have also observed that within the local day time interval (24 hours), the events occurred well before or after four of five MBSR and MASS, and five of six SRT and SST that showed no dipping (or, maintained 
Table 4: Trend of time variation of VLF amplitude, Dst and flare count during 23rd-28th October 2011 for GQD-A118 and DHO-A118 propagation path

\begin{tabular}{|c|c|c|c|c|c|c|c|c|}
\hline \multicolumn{9}{|c|}{ GQD-A118 propagation path } \\
\hline Date & \multicolumn{3}{|c|}{ Mean Signal peak (dB) } & \multicolumn{2}{|c|}{ Signal dip $(\mathrm{dB})$} & Dst (nT) & \multicolumn{2}{|c|}{ Flare count } \\
\hline & BSR & Mid-day & ASS & SRT & SST & $\sigma_{D s t}$ & $\geq C$ & C M X \\
\hline $23 / 10 / 11$ & $24.35 \pm 0.88$ & 16.59 & $21.83 \pm 0.87$ & -3.31 & -4.27 & \pm 4.08 & 3 & $\begin{array}{lll}3 & 0 & 0\end{array}$ \\
\hline $24 / 10 / 11$ & $21.63 \pm 1.02$ & 15.28 & $22.66 \pm 0.93$ & -6.35 & -4.89 & \pm 16.35 & 0 & 000 \\
\hline $25 / 10 / 11$ & $19.70 \pm 3.77$ & - & - & 2.16 & - & \pm 30.76 & 1 & 000 \\
\hline $26 / 10 / 11$ & $17.14 \pm 2.59$ & - & - & - & - & \pm 6.25 & 1 & 100 \\
\hline $27 / 10 / 11$ & $22.32 \pm 1.43$ & 17.45 & $21.74 \pm 1.33$ & -4.92 & -9.69 & \pm 3.53 & 1 & 100 \\
\hline $28 / 10 / 11$ & $21.83 \pm 0.86$ & 19.35 & $19.47 \pm 2.52$ & -4.97 & -11.98 & \pm 4.48 & 5 & 500 \\
\hline \multicolumn{9}{|c|}{ DHO-A118 propagation path } \\
\hline $23 / 10 / 11$ & $26.18 \pm 1.05$ & 10.45 & $25.51 \pm 0.82$ & -32.81 & -37.10 & \pm 4.08 & 3 & 300 \\
\hline $24 / 10 / 11$ & $25.53 \pm 0.92$ & 10.23 & $24.80 \pm 1.33$ & -26.64 & -30.84 & \pm 16.35 & 0 & 000 \\
\hline $25 / 10 / 11$ & $22.75 \pm 0.99$ & -2.12 & $22.16 \pm 1.68$ & -19.19 & -21.17 & \pm 30.76 & 1 & 100 \\
\hline $26 / 10 / 11$ & $25.51 \pm 1.22$ & 5.23 & $24.17 \pm 1.18$ & -34.30 & -15.40 & \pm 6.25 & 1 & 100 \\
\hline $27 / 10 / 11$ & $26.49 \pm 1.72$ & 8.16 & $22.53 \pm 4.45$ & -25.25 & -23.23 & \pm 3.53 & 1 & 100 \\
\hline $28 / 10 / 11$ & $23.96 \pm 1.68$ & 11.02 & $20.42 \pm 1.32$ & -29.63 & -37.10 & \pm 4.48 & 5 & 500 \\
\hline
\end{tabular}

amplitude) in accordance with the events. Among other possible inferences, this trend suggest that geomagnetic effects are not expected on any aspect of the signal (e.g., MBSR, MDP, MASS, SRT, SST) before significant geomagnetic perturbations, and if the event occurs well before the component, the induced ionospheric perturbations is expected to have significantly reduced at the time interval. Of the three propagation paths, the signal of DHO-A118 appears to be the most sensitive to geomagnetic induced magnetosphereionospheric dynamics. However, given the few number of the cases analysed so far, drawing a firm conclusion would be difficult at this stage. Therefore, we include more cases in the next analysis (see Table 4), and combine different signal aspects on a single graph for a better view of the trends.

We analyse and study the trend in variations of combined signal aspects for 16 storm cases (Dst=-50 to -132) between February 2011 and June 2012 for two propagation paths (GQD-A118 and DHO-A118). Details of the storm events are provided in Table 4. Analysis include taking (a) signal metrics (MBSR, MDP, MASS, SRT and SST) 1-day before an event (BE), during an event (DE) and after an event (AE), and (b) a 2-day mean signal metric 
Table 5: Summary of analysed geomagnetic storm conditions

\begin{tabular}{|c|c|c|c|c|}
\hline No. & Date & Max Dst (nT) & $\sigma_{D s t}$ & Flare count $(\geq C)$ \\
\hline & & & & C M X \\
\hline 1 & 05022011 & -51 & \pm 8.99 & 000 \\
\hline 2 & 01032011 & -81 & \pm 36.28 & 700 \\
\hline 3 & 06042011 & -65 & \pm 24.31 & 300 \\
\hline 4 & 12042011 & -51 & \pm 22.11 & 300 \\
\hline 5 & 26092011 & -101 & \pm 50.73 & 920 \\
\hline 6 & 25102011 & -132 & \pm 30.76 & 100 \\
\hline 7 & 22012012 & -67 & \pm 37.00 & 400 \\
\hline 8 & 15022012 & -58 & \pm 9.63 & 000 \\
\hline 9 & 19022012 & -54 & \pm 12.8 & 100 \\
\hline 10 & 07032012 & -74 & \pm 25.41 & 100 \\
\hline 11 & 15032012 & -74 & \pm 20.75 & 100 \\
\hline 12 & 28032012 & -55 & \pm 12.09 & 100 \\
\hline 13 & 05042012 & -54 & \pm 13.82 & 300 \\
\hline 14 & 23042012 & -95 & \pm 32.23 & 300 \\
\hline 15 & 12062012 & -51 & \pm 12.47 & 1300 \\
\hline 16 & 16062012 & 95 & \pm 20.24 & 400 \\
\hline $17^{*}$ & 17062012 & 80 & \pm 46.75 & 700 \\
\hline
\end{tabular}

$\mathrm{BE}, \mathrm{DE}$ and $\mathrm{AE}$. An event is selected based on factors such as availability and quality of VLF signal data on the day, and relatively quiet $\mathrm{BE}$ and $\mathrm{AE}$, particularly for the 2-day mean analysis. Although $\mathrm{BE}$ and $\mathrm{AE}$ data were carefully chosen to be consistent with relative geomagnetic quiet condition, a few choices on significantly perturbed days were unavoidable due to intervals of extended geomagnetic active condition and recurrent storms. This scenario can cause high variability of VLF radio signal. Other than solar induced fluctuations, the ionosphere and VLF radio signal also response to effects originating from a number of other sources (see Section 1.1). Some of the effects are interconnected (with possible interference), leading to a high variability of signal strength. Therefore, a 'perfect' consistency in trend across all the cases are not expected. Figure 11 shows Dst deviation (fluctuation) and trend in variation of signals MDP, MBSR, MASS, SRT and SST one day before and after (successive) each of the 16 selected storm conditions for (a) GQD-A118 and (b) DHO-A118 propagation paths. Detail of the data is provided in appendix I.

For GQD-A118 propagation path, 10 of 14 MDP, 10 of 15 MBSR, 7 of 

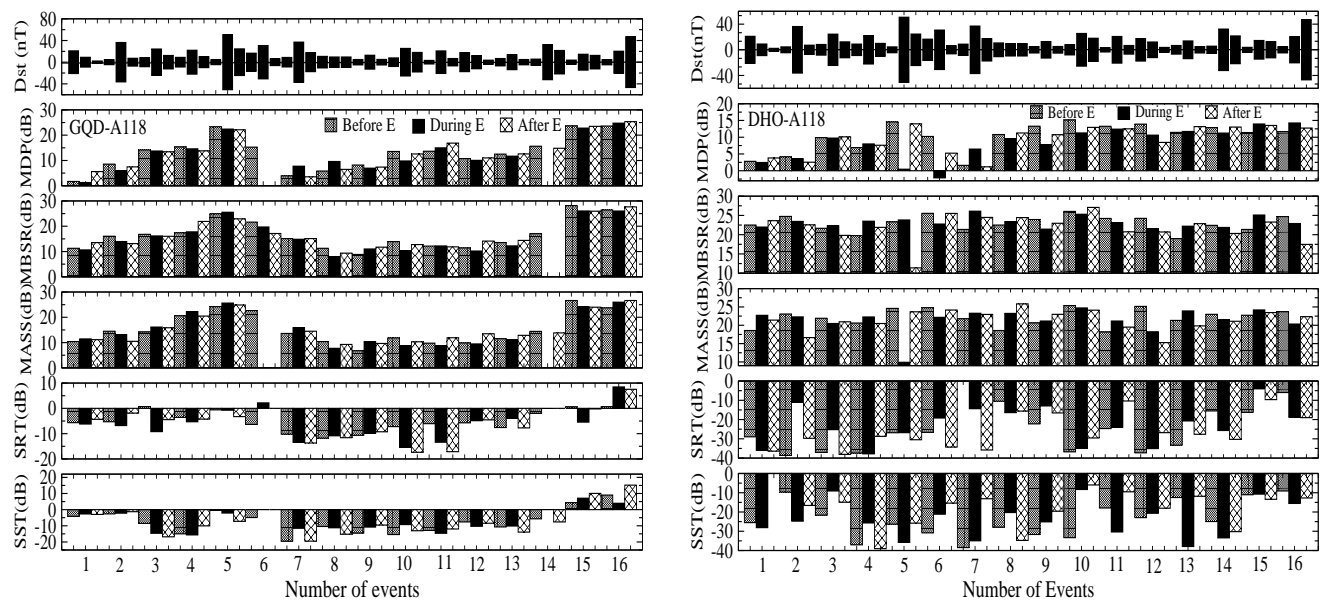

Figure 11: Daily Dst deviation and trend in variation of MDP, MBSR, MASS, SRT and SST signals one day before and after each of the 16 selected storm conditions for (a) GQD-A118 and (b) DHO-A118 propagation paths. A '0' indicate absence of data.

14 MASS, 9 of 14 SRT and 7 of 14 SST have shown a dipping of the signals. These correspond respectively to $71.4 \%, 66.7 \%, 50 \%, 64.3 \%$ and $50.0 \%$ of the combined cases. In DHO-A118 propagation path 13 of $16 \mathrm{MDP}, 9$ of 16 MBSR, 8 of 16 MASS, 5 of 14 SRT and 7 of 16 SST showed dipping of the signals. These correspond respectively to $81.3 \%, 56.3 \%, 50 \%, 35.7 \%$ and $43.8 \%$ of the combined cases. Note that dipping of any of DE and $\mathrm{AE}$ signal metric in cases 15 and 16 is taken as a response to the event because storm condition or the event commenced during late DE and peaked in AE. Also, recurrent storms occurred on the day after case 16 . Whereas majority of MDP in both the propagation paths have shown a notable evidence of dipping, few number of PP-mismatched incidences of MDP signal rise (or, increase) on some events day have been observed (e.g., events 8, 11 and 16 in GQD and 4 and 13 in DHO). The increase may be related to flare induced signal amplitude spike on the signal or phenomena arising from sources other than storm events. We also observed a notable matched-increase of the diurnal signal level (including MDP, MBSR and MASS) on DE 7 (22 Jan 2012) in both propagation paths. While further investigation is vital to accurate interpretation, a closer look at the available data showed occurrence of storm associated M-class flare with corresponding peaks, suggesting an enhancement of not only the instantaneous but also background X-ray flux output. 

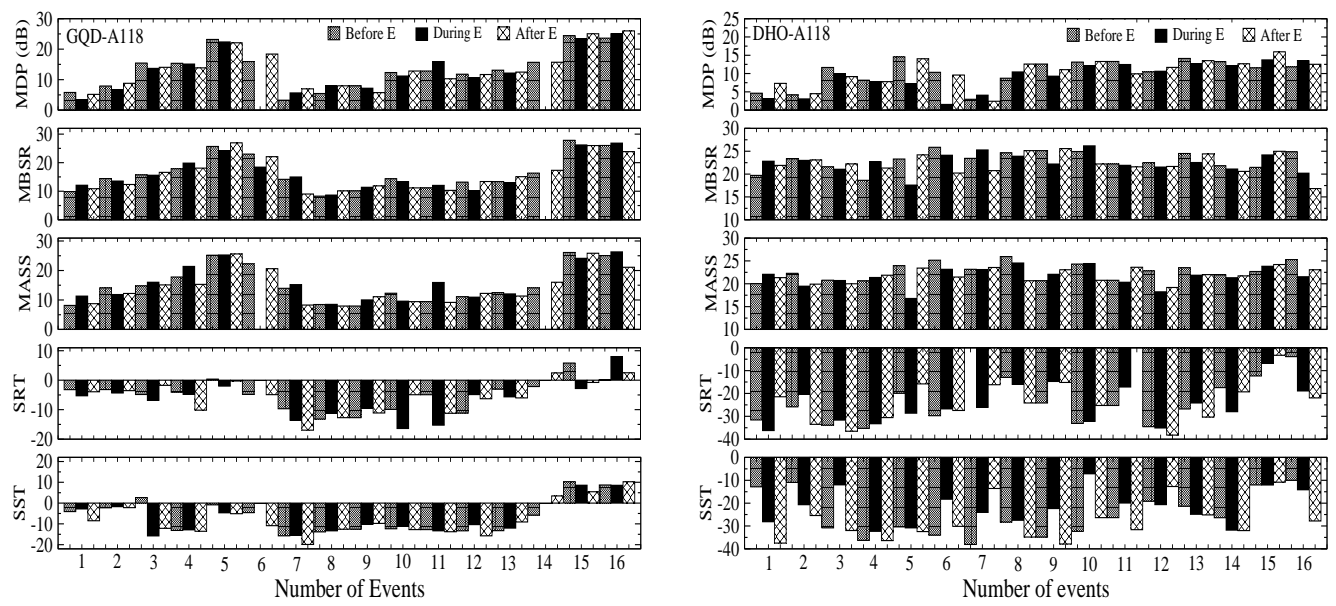

Figure 12: Daily Dst deviation (fluctuation) and trend in variation of 2-day mean MDP, MBSR, MASS, SRT and SST before, during and after an event for (a) GQD-A118 and (b) DHO-A118 propagation paths. A '0' indicate absence of data

Figure 12 shows Dst deviation (fluctuation) and trend in variation of 2-day mean MDP, MBSR, MASS, SRT and SST signals before, during and after each event for (a) GQD-A118 and (b) DHO-A118 propagation paths. Details of the data is provided in Appendix II. Using a different criterion for data selection, the analysis presented in Fig. 12 is a follow up on the one presented in Fig. 11, and expected to provide resourceful clue towards a better conclusion of the results. Whereas $\mathrm{BE}, \mathrm{DE}$ and $\mathrm{AE}$ represent data of three consecutive days with reference to the event's day (DE) in the former analysis (Fig 11), each acronym (BE, DE or AE) represent a 2-day mean (VLF) with respect to DE (but not necessarily in succession to DE). Besides data availability and quality, an important data selection criterion is a relative geomagnetic quiet BE- and AE-day with respect to DE - hence, a one or more days gap before or after DE (in some cases).

For GQD-A118 propagation path, 10 of 14 MDP, 9 of 15 MBSR, 7 of 14 MASS, 11 of 16 SRT and 5 of 14 SST showed dipping of the signals. These correspond respectively to $71.4 \%, 60.0 \%, 50.0 \%, 68.8 \%$ and $35.7 \%$ of the combined cases. For DHO-A118 propagation path, 11 of 16 MDP, 11 of 16 MBSR, 10 of 16 MASS, 6 of 14 SRT and 7 of 16 SST showed dipping of the signals, corresponding respectively to $68.8 \%, 68.8 \%, 62 \%, 42.9 \%$ and $43.8 \%$ 
of the combined cases. In general, MDP signal has shown a high probability of a dipping scenario following significant geomagnetic disturbance or storm condition. The MBSR and MASS signals have also shown good probability of exhibiting such storm-induced dipping, but appear to be influenced by event's occurrence time and the highly variable conditions of dusk-to-dawn ionosphere. However, a fewer cases have shown a rise or increase of the components instead (e.g., MDP, MBSR, MASS) following a significant geomagnetic event. We speculate that such a scenario (signal rise) may be related to storm associated phenomena or of sources other than solar origin rather that being a case against the 'favoured' dipping - this need be studied further. In contrast, the SRT and SST signals have shown significant post-storm dipping in GQD-A118 propagation path but mostly increase in DHO-A118 propagation path. Does the trend in post-storm SRT and SST variation depend on signal propagation path? This important question may not be conclusively answered based on this present analysis. Thus, a clear dependence of SRT and SST on geomagnetic disturbance or storm conditions seems inconclusive.

We consider it to be important to highlight the constraints associated with this analysis that may have also influenced our results and findings. Besides the flare and X-ray flux induced amplitude variation (see, Fig 2c), the daytime diurnal signal between SRT and SST of VLF radio waves are generally quite stable. No doubt, their stability has contributed to the consistency of MDP trend in the overall pattern of the results - the combined analysis showed about $73 \%$ dipping of the MDP. On the other hand, high variability or fluctuation of dusk-to-dawn signal (see, Fig. 2a-d) remain a major drawback to analysis relating to MBSR and MASS - the combined analysis showed $63 \%$ and $53 \%$ dipping of the MBSR and MASS, respectively. Similarly, the pseudo-SRT and SST (occurrence of double or multiple-tipped sunrise and/or sunset terminator) exhibited by diurnal VLF signal also hampers proper analysis of the signals - the combined analysis showed $52 \%$ and $43 \%$ dipping of the SRT and SST, respectively. Deciding which of the tips to measure (in case of a pseudo-SRT/SST) would be more important but challenging. Nevertheless, a proper study which probes the cause of such fluctuations and occurrence of pseudo-terminators in VLF signature will be highly valuable. Such a study in addition to further investigating the observed interesting propagation paths (matched and mismatched) signal-rise during some cases of geomagnetic storm conditions have been initiated. This is beyond the scope of the present work and will be published elsewhere in 
due course.

\section{Summary and Conclusion}

The characteristic response of diurnal VLF signal to space weather induced ionospheric disturbances vary from one propagation path to another, and also depend on location of the transmitters and receivers, ionisation and chemistry of the D region over the propagation path, and the intensity of induced perturbations. Other influencing factors include signal frequency and nature of Earth's surface (also see, Mimno, 1937; Poole, 1999; Melia, 2010). In principle, known strong perturbations from solar flares and gamma-ray bursts of VLF signals can be reproduced from ab-initio calculations (Palit et al. 2013). In this paper, we used various aspect of diurnal VLF signal (such as MBSR, MDP, MASS, SRT and SST) to investigate the footprint of geomagnetic activity in D layer ionosphere at mid-latitude $\left(40^{\circ}-54^{\circ}\right)$ region, under varying degree of sixteen storm conditions (and consequent disturbances). Although the strength of diurnal signals significantly varied from one propagation path to another, the trend of variations of the characteristic signal appear to reflect the prevailing space weather conditions of various time scales. We found a significant dipping of the mid-day amplitude peak (MDP) of the signal within 1-2 days of significant geomagnetic disturbance or storm conditions. The MBSR and MASS signals have also generally shown such storm-induced dipping. However, they appear to be influenced by events' occurrence time and highly variable condition of dusk-to-dawn ionosphere. We observed a fewer cases of rise of the signals (e.g., MDP, MBSR or MASS) following a significant geomagnetic event. However, this may be related to storm-associated events or due to effects arising from sources other than solar origin. The extent of the induced dipping (or, rise) significantly depends on the intensity and duration of event(s), as well as the propagation path of the signal. The post-storm day signal (following a main event, with lesser or significantly reduced geomagnetic activity), exhibited a tendency of recovery to pre-storm day level. In the present analysis, the post-storm SRT and SST variations do not appear to have a well defined trend - the SRT and SST signals have shown more post-storm dipping in GQD-A118 propagation path but mostly increase in DHO-A118 propagation path.

Many researchers have investigated and reported ionospheric and VLF signal anomalies before seismic events (e.g., Hayakawa et al., 2010; Ray 
and Chakrabarti, 2013; Sasmal et al., 2014). Such anomalies were often attributed to seismicity and therefore viewed as pre-cursors. However, in order to ensure that such VLF anomalies are indeed due to seismic events, it is imperative that other possible and potential drivers of ionospheric anomalies around intervening period are investigated, identified and separated. In future, we will investigate possible solar and geomagnetic-induced perturbations of the ionosphere within the time frame in which ionospheric precursor (using VLF signal) were reported. This must be taken into consideration before marking anomalies as pre-cursors. For this two prong approach is necessary: (i) to reproduce propagation path dependent effects on VLF signals due to number of specific types of solar induced perturbations as in Palit et al. (2013) and (ii) to find statistical correlations among various quantities using data for longer duration. The work is in progress and would be published elsewhere.

\section{Acknowledgment}

Victor U.J.N. acknowledge TWAS/ICTP, Trieste, Italy and the S.N. Bose National Centre for Basic Sciences for the research fellowship during which this work was done. Authors thank Dr. William Denig (NOAA), Margaret Tilton (NOAA affiliate at Cooperative Institute for Research in Environmental Sciences (CIRES), University of Colorado at Boulder) and Daniel Wilkinson (NOAA) for their help with relevant data link and tips. Authors also acknowledge NOAA, WDCG, SWEPAM and A118 SID database.

\section{References}

Alfonsi, L., Kavanagh, A. J., Amata, E., Cilliers, P., Correia, E., Freeman, M., Kauristie, K., Liu, R. Y., Luntama, J. P., Mitchell, C. N. and Zherebtsov, G. A., 2008. Probing the high latitude ionosphere from groundbased observations: The state of current knowledge and capabilities during IPY (2007-2009). Journal of Atmospheric and Solar-Terrestrial Physics, 70 (18), pp. 2293-2308.

Araki T., 1974. Anomalous Phase Changes of Trans equatorial VLF Radio Waves during Geomagnetic Storms. Journal of Geophysical Research, 79, 4811-4813. 
Baker D. N., 1996. Solar wind-magnetosphere drivers of space weather. J. Atm. Solar-Terres. Phys., 58, 15OW526.

Baker D. N., 2000. E ects of the Sun on the Earth's environment. J. Atm. Solar-Terres. Phys., 62, 1669-1681.

Basak T., S. Pal and S. K. Chakrabarti, 2011. VLF study of Ionospheric properties during solar flares of varied intensity for a fixed propagation path. General Assembly and Scientific Symposium, 2011 XXXth URSI, 13-20 Aug. 2011, doi: 10.1109/URSIGASS.2011.6051004.

Borovsky J. E. and Denton M. H., 2006. Differences between CME-driven storms and CIR-driven storms'. Journal of Geophysical Research, 111.

Burke W. J., 2000. Magnetosphere-ionosphere coupling: selected topics. Journal of Atmospheric and Solar-Terrestrial Physics 62, 817-824.

Bucha, V., Bucha Jr. V., 1998. Geomagnetic forcing of changes in climate and in the atmospheric circulation. J. Atmos. Sol-Terr. Phys. 60 (2), 145-169.

Buonsanto M. J., 1999. Ionospheric Storms - A Review, Space Science Reviews, 88, 563-601, 1999

Chakrabarti S. K., M. Saha, R. Khan, Mandal, S., Acharyya, K., and Saha, R., 2005. Possible Detection of Ionospheric Disturbances during SumatraAndaman Islands. IJRS Phys., 34, 314-317.

Chakrabarti, S. K., Sasmal, S., and Chakrabarti, S., 2010. Ionospheric anomaly due to seismic activities - Part 2: Evidence from D-layer preparation and disappearance times. Nat. Haz. Earth Syst. Sci., 10, 1751-1757.

Chen C. H., C. H. Lin, L. C. Chang, J. D. Huba, J. T. Lin, A. Saito, and J. Y. Liu, 2013. Thermospheric tidal effects on the ionospheric midlatitude summer nighttime anomaly using SAMI3 and TIEGCM, J. Geophys. Res. Space Physics, 118, 38363845, doi:10.1002/jgra.50340.

Chenette D.L., D. W. Datlowe, R. M. Robinson, T. L. Schumaker, R. R. Vondrak, and J. D. Winningham, 1993. Atmospheric energy input and ionization by energetic electrons during the geomagnetic storm of 8-9 November 1991, Geophys. Res. Lett., 20, 1323. 
Clilverd M. A., Rodger C. J., Gamble R. J., Ulich T., Raita T., Seppala A., Green J. C., Thomson N. R., Sauvaud J. A., and Parrot M., 2010. Ground-based estimates of outer radiation belt energetic electron precipitation fluxes into the atmosphere. Journal of Geophysical Research, 115, A12304.

Cranmer S. R., 2009. Coronal Holes. Living Rev. Solar Phys., 6, 3.

Danilov A. D. and Lastovicka J., 2001. Effects of Geomagnetic Storms on the Ionosphere and Atmosphere, International Journal of Geomagnetism and Aeronomy, 2, 209-224.

Goldstein J., Burch J. L., Sandel B. L., Mende S. B., P. C:son Brandt and Hairston M. R., 2005. Coupled response of the inner magnetosphere and ionosphere on 17 April 2002, Journal of Geophysical Research, 110, A03205, DOI:10.1029/2004JA010712

Goncharenko, L. P., A. J. Coster, R. A. Plumb, and D. I. V. Domeisen, 2012. The potential role of stratospheric ozone in the stratosphere-ionosphere coupling during stratospheric warmings, Geophys. Res. Lett., 39, L08101, doi:10.1029/2012GL051261

Greenwald, R. A., K. B. Baker, J. R. Dudeney, M. Pinnock, T. B. Jones, E. C. Thomas, J.-P. Villain, J.-C. Cerisier, C. Senior, C. Hanuise, R. D. Hunsucker, G. Sofko, J. Koehler, E. Nielsen, R. Pellinen, A. D. M. Walker, N. Sato, and H. Yamagishi, 1995. Darn/Superdarn: A Global View of the Dynamics of High-Latitude Convection, Space Sci. Rev., 71, 761796. doi:10.1007/BF00751350

Greenwald R. A., J. M. Ruohoniemi, W. A. Bristow, G. J. Sofko, J.-P. Villain, A. Huuskonen, S. Kokubun, and, L. A. Frank, 1996. Mesoscale dayside convection vortices and their relation to substorm phase, Journal of Geophysical Research, 101, 21,697-21,713.

Grubor D., Sulic D., and Zigman V., 2005. Influence of solar X-ray flares on the Earth-ionosphere waveguide. Serbian Astronomical J, 171, 29-35.

Hamilton D. C., Gloeckler G., Ipavich F. M., Stdemann W., Wilken B. and Kremser G., 1988. Ring current development during the great geomagnetic storm of February 1986'. Journal of Geophysical Research: Space Physics, 93, pp 14343-14355. 
Han F. and S. A. Cummer, 2010. Midlatitude nighttime D region ionosphere variability on hourly to monthly time scales. J. Geophys. Res., 115, A09323, doi:10.1029/2010JA015437.

Hayakawa M, O. A. Molchanov, Ondoh T. and Kawai E., 1996. The precursory signature effect of Kobe earthquake on VLF subionospheric signals. Phys. Earth Planet. Inter., 57, pp 64-67.

Heikkila W., 2011. Earth's Magnetosphere. Elsevier Kidlington, Oxford, UK.

Hejda P. and Bochncek J., 2005. Geomagnetically induced pipe-to-soil voltages in the Czech oil pipelines during OctoberNovember 2003. Annales Geophysicae, 23, 3089-3093.

Honary F, Stocker A. J., Robinson T. R. and Jones T. B., 1995. Ionospheric plasma response to $\mathrm{HF}$ radio waves operating at frequencies close to the third harmonic of electron gyrofrequency. J. Phys. Res., 100, 21489-21501.

Kelley M. C., 1989. The Earth's Ionosphere. Academic Press Inc. San Diego, California.

Kikuchi T. and Evans D.S., 1983. Quantitative study of substorm-associated VLF phase anomalies and precipitating energetic electrons on November 13, 1979. J. Geophys. Res., Space Phys., 88, 871-880.

Kleimenova N. G., Kozyreva O. V., Rozhnoy A. A. and Soloveva M. S., 2004. Variations in the VLF signal parameters on the Australia-Kamchatka radio path during magnetic storms. Geomagn Aeron 44, 385-393.

Kozyra J. U, G. Crowley, B. A. Emery, X. Fang, G. Maris, M. G. Mlynczak, R. J. Niciejewski, S. E. Palo, L. J. Paxton, C. E. Randall, P.-P. Rong, J. M. Russell III, W. Skinner, S. C. Solomon, E. R. Talaat, Q. Wu and J.-H. Yee, 2006. Response of the Upper/Middle Atmosphere to Coronal Holes and Powerful High-Speed Solar Wind Streams in 2003. Recurrent Magnetic Storms: Corotating Solar Wind Streams. Geophysical Monograph 167. Edited by Bruce Tsurutani, Robert McPherron, Walter Gonzalez, Gang Lu, Jos H. A. Sobral and Natchimuthukonar Gopalswamy. ISBN-13: 9780-87590-432-0. AGU Books Board, AGU, Washington, DC USA, 319.

Kumar A. and Kumar S., 2014. Space weather effects on the low latitude D-region ionosphere during solar minimum. Earth, Planets and Space, 66. 
Kutiev I., Ioanna Tsagouri, Loredana Perrone, Dora Pancheva, Plamen Mukhtarov, Andrei Mikhailov, Jan Lastovicka, Norbert Jakowski, Dalia Buresova, Estefania Blanch, Borislav Andonov, David Altadill, Sergio Magdaleno, Mario Parisi and Joan Miquel Torta, 2013. Solar activity impact on the Earths upper atmosphere. Journal of Space Weather and Space Climate, 3 .

Lastovicka J., 1989. Solar wind and high energy particle effects in the middle atmosphere, Handb. MAP, 29, 119.

Lastovicka J., 1996. Effects of geomagnetic storms in the lower ionosphere, middle atmosphere and troposphere, Journal of Atmospheric and Terrestrial Physics, 58, 831-843.

Leonard J. M., Forbes J., and Born G. H., 2012. Impact of tidal density variability on orbital and reentry predictions, J. Geophys. Res.: Space Weather, 10, S12003, doi:10.1029/2012SW000842

McRae W. M. and Thomson N. R., 2004. Solar flare induced ionospheric D-region enhancements from VLF phase and amplitude observations, Journal of Atmospheric and Solar-Terrestrial Physics, 66, 77-87. DOI:10.1016/j.jastp.2003.09.009

Melia A., 2010. Flare Detection using VLF Radio Signal, G3NYK.

Miller N. J. and Brace L. H., 1969. Some winter characteristics of the northern high-latitude ionosphere, Journal of Geophysical Research, 74, 5752-5762.

Mimno H. R., 1937. The Physics of the Ionosphere, Reviews of Modern Physics, 9, 1-45.

Mitra W. B., 1974. Ionospheric effects of solar flares. D. Reidel Publishing Company, Dordrecht, Holland.

Molchanov O. A. and Hayakawa M., 1998. On the generation mechanism of ULF seimogenic electromagnetic emissions, Phys. Earth Planet. Int., 105, 201-220.

Nwankwo V. U. J and Chakrabarti K. S., 2014. Theoretical Modeling of Drag Force Impact on a Model International Space Station (ISS) during Variation of Solar Activity. Trans. JSASS Aerospace Technology Japan , 12 , pp $47-53$ 
Nwankwo V. U. J. and Chakrabarti S. K., 2014. A Probe of magnetosphereionosphere coupling using Very Low Frequency (VLF) Radio Signal from North-West Cape (Australia) to Kolkata (India). 40th COSPAR Scientific Assembly. Held 2-10 August 2014, in Moscow, Russia, C0.4-21-14.

Nwankwo V. U. J., Sandip K. Chakrabarti and Weigel R. S., 2015. Effects of Plasma Drag on Low Earth Orbiting Satellites due to solar forcing induced perturbations and Heating. Adv. Space Res., 56, 47-56.

Nwankwo V. U. J., Chakrabarti S. K., Sasmal S. and Ray S., 2016. Possible influence of solar activity on some seismically induced precursors through Magnetosphere-ionosphere coupling. J. Geophys. Res., 2016JA022468 (submitted)

Pal S., Surya K. Maji and Sandip K. Chakrabarti, 2012. First ever VLF monitoring of the lunar occultation of a solar flare during the 2010 annular solar eclipse and its effects on the D-region electron density profile, Planetary and Space Science, 73, 310-317.

Palit S., Basak T., S. K. Mondal, S. Pal, and S. K. Chakrabarti, 2013. Modeling of very low frequency (VLF) radio wave signal profile due to solar flares using the GEANT4 Monte Carlo simulation coupled with ionospheric chemistry, Atmos. Chem. Phys., 13, 9159-9168.

Pancheva D. V., P.J. Mukhtarov, N.J. Mitchell, D.C. Fritts, D.M. Riggin, H. Takahashi, P.P. Batista, B.R. Clemesha, S. Gurubaran, G. Ramkumar, 2008. Planetary wave coupling (56-day waves) in the low-latitude atmosphere-ionosphere system. J. Atm. Solar-Terr. Phy., 70, 101-122.

Peter W. B., Chevalier M. W., and Inan U. S., 2006. Perturbations of midlatitude sub-ionospheric VLF signals associated with lower ionospheric disturbances during major geomagnetic storms. Journal of Geophysical Research, 111, AO3301.

Polyakov A. S., M.A. Chernigovskay, N.P. Perevalov, 2014. Ionospheric effects of sudden stratosphere warmings in Eastern Siberian region. J. Atm. SolarTerr. Phys., 120, 15-23.

Poole I., 1999. Radio Waves and the Ionosphere. American Radio Relay League, G3YWX. 
Prolss G. W., 2004. Physics of the Earth's space environment. Springer Berlin Heidelberg, Germany.

Raulin, J.-P., Pacini, A.A., Kaufmann, P., Correia, E., Martinez, M.A.G., 2010. On the detectability of solar X-ray flares using very low frequency sudden phase anomalies. Journal of Atmospheric and Solar-Terrestrial Physics 68, 1029-1035.

Raulin J-P., Fernando C. P. Bertoni, Hernan R. Gaviln, Walter Guevara-Day, Rodolfo Rodriguez, Germn Fernandez, Emilia Correia, Pierre Kaufmann, Alessandra Pacini, Tardelli R. C. Stekel, Washington L. C. Lima, Nelson J. Schuch, Paulo R. Fagundes and Rubens Hadano, 2010. Solar flare detection sensitivity using the South America VLF Network (SAVNET). Journal of Geophysical Research, 115, A07301. DOI: 10.1029/2009JA015154

Raulin J-P, Grard Trottet, Matthieu Kretzschmar, Edith L. Macotela, Alessandra Pacini, Fernando C. P. Bertoni and Ingolf E. Dammasch, 2013. Response of the low ionosphere to X-ray and Lyman- solar flare emissions. Journal of Geophysical Research, 118, 570-575. DOI: 10.1029/2012JA017916

Ray S. and Chakrabarti S. K., 2012. A study of the behavior of the terminator time shifts using multiple VLF propagation paths during the Pakistan earthquake $(M=7.2)$ of 18 January 2011. Nat. Hazards Earth Syst. Sci., 13, pp 1501-1506.

Ruohoniemi J.M., and Greenwald R.A., 2005. Dependencies of high-latitude plasma convection: consideration of interplanetary magnetic field, seasonal, and universal time factors in statistical patterns. Journal of Geophysical Research, 110, A09204, doi:10.1029/2004JA010815

Russell, A. J. B., A. N. Wright, and A. W. Hood, 2010. Self-consistent ionospheric plasma density modifications by field-aligned currents: Steady state solutions. J. Geophys. Res., 115, A04216, doi:10.1029/2009JA014836.

Russell, A. J. B., and A. N. Wright, 2012. Magnetosphere-ionosphere waves. J. Geophys. Res., 117, A01202, 2012. doi:10.1029/2011JA016950

Sasmal S. and S. K. Chakrabarti, 2009. Ionosperic anomaly due to seismic activities Part 1: Calibration of the VLF signal of VTX $18.2 \mathrm{KHz}$ station 
from Kolkata and deviation during seismic events. Nat. Hazards Earth Syst. Sci., 9, 1403-1408.

Simoes F., Pfaff R., Berthelier J. and Klenzing, 2012. A Review of Low Frequency Electromagnetic Wave Phenomena Related to TroposphericIonospheric Coupling Mechanisms. Space Science Reviews, 168, 551-593.

Singer H. J., Matheson L., Grubb R., Newman A. and Bouwer S. D., 1996. Monitoring space weather with the GOES magnetometers. NOAA Space Environment Center.

Stoker P. H., 1993. Energetic Electron Power Flux Deposition at Sanae $(\mathrm{L}=4.0)$ from Riometer Recording. Journal of Geophysical Research, 98, 19111-19116.

Streltsov A. V. and W. Lotko, 2004. Multiscale electrodynamics of the ionosphere-magnetosphere system. J. Geophys. Res., 109, A09214. doi:10.1029/2004JA010457.

Tatsuta K., Hobara Y., Pal S. and Balikhin M., 2015. Sub-ionospheric VLF signal anomaly due to geomagnetic storms: a statistical study. Ann. Geophys., 33, 1457-1467.

Thomson N. R., Rodger C. J. and Dowden R. L., 2004. Ionosphere gives size of greatest solar flares. Geophys Res Lett 31, L06803.

Tsurutani B. T. and Meng C. I., 1972. Interplanetary magnetic field variations and substorms. J. Geophys. Res., 77, 2964-2970.

Tsurutani B. T., Gonzalez W. D., Tang F., Akasofu S. I., and Smith E. J., 1988. Origin of interplanetary southward magnetic fields responsible for major magnetic storms near solar maximum (1978-1979). J. Geophys. Res., 93, 8519-8531.

Tsurutani B. T., Gonzalez W. D., Gonzalez A. L. C., Tang F., Arballo J. K., and Okada M., 1995. Interplanetary origin of geomagnetic activity in the declining phase of the solar cycle. J. Geophys. Res., 100, 21717-21733.

Tsurutani B. T. and Gonzalez W. D., 1997. The interplanetary causes of magnetic storms: A review, in: Magnetic Storms.Edited by: Tsurutani, B. T., Gonzalez, W. D., Kamide, Y., and Arballo, J. K., Amer. Geophys. Un. Press, Wash. D.C., 98, 77-89. 
Tsurutani B. T., Gonzalez W. D., Gonzalez A. L. C., Guarnieri F. L., Gopalswamy N., Grande M., Kamide Y., Kasahara Y., Lu G., Mann I., McPherron R. L., Soraas F., and Vasyliunas V. M., 2006. Corotating solar wind streams and recurrent geomagnetic activity: A review. J. Geophys. Res., 111, A07S01, doi:10.1029/2005JA011273

Tsurutani B. T., Echer E., Guarnieri F. L. and Gonzalez W. D., 2011. The properties of two solar wind high speed streams and related geomagnetic activity during the declining phase of solar cycle 23. J. Atmos. Solar-Terr. Phys., 73, 164, doi:10.1016/j.jastp.2010.04.003

Tsurutani B. T., Echer E., and Gonzalez W. D., 2011. The solar and interplanetary causes of the recent minimum in geomagnetic activity (MGA23): a combination of midlatitude small coronal holes, low IMF BZ variances, low solar wind speeds and low solar magnetic fields. Ann. Geophys., 29, 839-849.

Wait J. R., 1959. Diurnal change of ionospheric heights deduced from phase velocity measurements at VLF. Proc. IRE, 47, 998.

Wait J. R. and Spies K. P., 1964. Characteristics of the Earth-ionosphere wave-guide for VLF radio waves. NBS Tech. Note 300.

Weigel R. S., 2010. Solar wind density influence on geomagnetic storm intensity. J. Geophys. Res., 115, A09201, doi:10.1029/2009JA015062.

Wild J.A., Milan S.E., Cowley S.W.H., Dunlop M.W., Owen C.J., Bosqued J.M., Taylor M.G.G.T., Davies J.A., Lester M., Sato N., Yukimatu A.S., Fazakerley A.N., Balogh A., Re'me H., 2003. Coordinated interhemispheric SuperDARN radar observations of the ionospheric response to flux transfer events observed by the Cluster spacecraft at the high-latitude magnetopause. Ann Geophys, 21, 1807-1826.

Zhang S., Fukao S., Oliver W. L., and Otsuka Y., 1999. The height of the maximum ionospheric electron density over the MU radar, Journal of Atmospheric and Solar-terrestrial Physics, 61, 1367-1383, DOI:10.1016/S1364-6826(99)00088-7 


\section{Figure Captions}

Figure 1: VLF signal propagation paths used in the study

Figure 2: Diurnal signature of VLF signals showing the aspects of the analysed signal

Figure 3: (a) Diurnal VLF amplitude for GQD-A118 PP (b) Diurnal VLF amplitude for ICV-A118 PP (c) X-ray flux output (d) solar wind speed $\left(V_{s w}\right)$ (d) $B_{z}$ magnetic field component (e) $H_{T}$ magnetic field (f) Dst and (g) $A_{p}$ variations during 14-19th February 2011

Figure 4: Daily Dst standard deviation, 4-hour mean signal amplitude before sunrise (MBSR), mid-day signal peak (MDP), 4-hour mean signal amplitude after sunset (MASS), sunrise terminator (SRT) and sunset terminator (SST) variations for (a) GQD-A118 and (b) ICV-A118 propagation path during 14-19th February 2011

Figure 5: (a) Diurnal VLF amplitude for GQD-A118 PP (b) Diurnal VLF amplitude for ICV-A118 PP (c) X-ray flux (d) $V_{s w}$ (d) $B_{z}$ (e) $H_{T}$ (f) Dst and (g) $A_{p}$ variations during 26th-31st May 2011

Figure 6: Daily Dst standard deviation, 2-hour MBSR, MDP, 2-hour MASS, SRT and SST variations for (a) GQD-A118 and (b) ICV-A118 propagation path during 26th-31st May 2011

Figure 7: (a) Diurnal VLF amplitude for GQD-A118 PP (b) Diurnal VLF amplitude for DHO-A118 PP (c) X-ray flux (d) $V_{s w}$ (d) $B_{z}$ (e) $H_{T}$ (f) Dst and $(\mathrm{g}) A_{p}$ variations during 24th-29th September 2011

Figure 8: Daily Dst standard deviation, 4-hour MBSR, MDP, 4-hour MASS, SRT and SST variations for (a) GQD-A118 and (b) DHO-A118 propagation path during 24th-29th September 2011

Figure 9: (a) Diurnal VLF amplitude for GQD-A118 PP (b) Diurnal VLF amplitude for DHO-A118 PP (c) X-ray flux (d) $V_{s w}$ (d) $B_{z}$ (e) $H_{T}$ (f) Dst and $(\mathrm{g}) A_{p}$ variations during 23rd-28th October 2011 
873 Figure 10: Daily Dst standard deviation, 4-hour MBSR, MDP, 4-hour MASS, 874 SRT and SST variations for (a) GQD-A118 and (b) DHO-A118 propagation 875 path during 23rd-28th October 2011

876

877 Figure 11: Daily Dst deviation (fluctuation) and trend in variation of signals 878 MDP, MBSR, MASS, SRT and SST one day before and after each of the 16 879 selected storm conditions for (a) GQD-A118 and (b) DHO-A118 propagation 880 paths. A '0' indicate absence of data

Figure 12: Daily Dst deviation (fluctuation) and trend in variation of 2-day mean MDP, MBSR, MASS, SRT and SST before, during and after an event for (a) GQD-A118 and (b) DHO-A118 propagation paths. A '0' indicate absence of data 